Review

\title{
High Strength and High Modulus Electrospun Nanofibers
}

\author{
Jian Yao ${ }^{1}$, Cees W. M. Bastiaansen ${ }^{1,2}$ and Ton Peijs ${ }^{1,3, *}$
}

1 School of Engineering and Materials Science, and Materials Research Institute, Queen Mary University of London, Mile End Road, London E1 4NS, UK; E-Mails: j.yao@qmul.ac.uk (J.Y.); C.W.M.Bastiaansen@tue.nl (C.W.M.B.)

2 Faculty of Chemistry and Chemical Engineering, Eindhoven University of Technology, P.O. Box 513, 5600 MB Eindhoven, The Netherlands;

3 Nanoforce Technology Ltd., Joseph Priestly Building, Queen Mary University of London, Mile End Road, London E1 4NS, UK;

* Author to whom correspondence should be addressed; E-Mail: t.peijs@qmul.ac.uk; Tel.: +44-(0)20-7882-8865.

Received: 12 February 2014; in revised form: 19 March 2014 / Accepted: 9 April 2014 / Published: 30 April 2014

\begin{abstract}
Electrospinning is a rapidly growing polymer processing technology as it provides a viable and simple method to create ultra-fine continuous fibers. This paper presents an in-depth review of the mechanical properties of electrospun fibers and particularly focuses on methodologies to generate high strength and high modulus nanofibers. As such, it aims to provide some guidance to future research activities in the area of high performance electrospun fibers.
\end{abstract}

Keywords: polymer nanofibers; chain orientation; chain extension; crystallinity; mechanical properties; carbon nanotubes; carbon nanofibers

\section{Introduction}

Over the last two decades, a relatively old technique, electrospinning, has been receiving renewed interest due to its huge potential of producing polymer nanofibers [1-3]. Since then, basic electrospinning theories [4-6] have been developed and hundreds of electrospun nanofibers from different polymer systems have been practically produced [7-9]. 
The small fiber diameter (usually $20 \mathrm{~nm}-1 \mu \mathrm{m}$ ), high specific surface area (tens to hundreds $\mathrm{m}^{2} / \mathrm{g}$ ), high porosity and small pore size renders electrospun nanofibers of interest for a wide range of potential applications in tissue engineering, drug delivery, textiles, filtration, composite reinforcements, etc. [10-12]. Many applications require however high mechanical property nanofibers and for applications like air filtration systems [13], microfibers are still employed as supports for electrospun fibers as these nanofibers are often too weak to be used independently.

Compared to corresponding textile fibers made from the same polymers, the mechanical properties of electrospun nanofibers are often found to be poor. Electrospun nanofibers typically display tensile strengths below $300 \mathrm{MPa}$ and Young's moduli below 3 GPa [12,14-19], which can be mainly ascribed to the low degree of orientation and chain extension of the polymer chains along the fiber axis. The objective of this review article is to report on the various research works on mechanical properties of electrospun nanofibers and to answer the question whether it is at all possible to produce high modulus and high strength electrospun nanofibers. For this, first a brief overview of different concepts to produce conventional high performance synthetic fibers will be given, focusing on flexible chain versus rigid chain polymers. Subsequently, we will discuss current progresses in the manufacturing of high performance electrospun nanofibers.

\section{High Strength and High Modulus Fibers}

\subsection{Basic Concepts for High Performance Fibers}

A century ago, natural fibers like cotton, silk, and wool dominated the market due to their abundance and aesthetic appeal. In the 1920s, Hermann Staudinger was the first to propose the concept of macromolecules [20] and this epoch-making idea greatly influenced the discovery of synthetic fibers with the first synthetic fiber being invented in 1935 by Wallace Carothers, which is known to us as polyamide (PA) or nylon fiber [21].

The two most commonly used aliphatic polyamide fibers are polyamide 6 and polyamide 6,6 which are made of caprolactam and hexamethylenediamine with adipic acid, respectively. Polyamide (PA) fibers are produced by melt-spinning and are given moderate molecular orientation and crystallinity after post-drawing. Molecular orientation and crystallinity, along with hydrogen bonding between chains provided by the amide group (-NH-CO-) [22] provides them with good mechanical properties and abrasion resistance, which renders them to be one of the most widely used industrial fibers. Polyethylene terephthalate (PET), which is the most important commercial polyester, first appeared on the market in 1953 [23] and is now fully established in textile and technical fibers. PET is produced by polymerization of either dimethyl terephthalate or terephthalic acid with ethylene glycol. Melt-spinning in combination post-drawing is also applied in the manufacture of PET fibers, with main applications in textiles, ropes, tyres, carpets, and so on. Since these initial developments on PA and PET, more and more synthetic fibers have been investigated and developed.

The tensile strength and Young's modulus of those traditional synthetic fibers are usually limited to below $1 \mathrm{GPa}$ and $15 \mathrm{GPa}$, respectively. The relatively low mechanical performance of these textile fibers greatly limits their applications in areas such as aerospace, protective clothing, armor, advanced composites, etc. 
In 1932, Staudinger [24] postulated the basic requirements for producing a high strength and high modulus synthetic fiber. In his structural model for such a fiber, all molecular chains should be fully extended and perfectly aligned along the fiber axis. Simultaneously, few chain end defects should exist as the tensile strength is determined by secondary bonds rather than primary bonds. The fully extended and oriented polymer chains will provide ultimate stiffness to the fiber while the few chain end defects as in the case of high molecular weight polymers provides high tenacity, the combination of both making the ideal fiber (Figure 1).

Figure 1. Ideal polymer chains model for producing high strength and high modulus fibers.

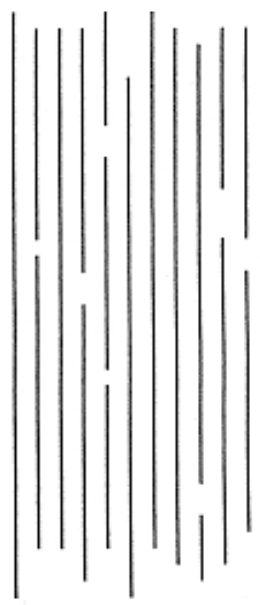

It has long been recognized by Meyer and Lotmar [25] that only extended polymer chains will provide high stiffness. In 1960, Terloar [26] estimated the longitudinal modulus of a single extended polyethylene chain to be $182 \mathrm{GPa}$ in comparison to the Young's modulus of isotropic polyethylene being less than 2 GPa [27]. More calculations showed that the Young's modulus of a single extended polyethylene chain can reach even higher values up to $320 \mathrm{GPa}$ [28]. On the other hand, polymers like polypropylene with a helical chain configuration, exhibit a much lower theoretical modulus compared with planar zig-zag configurations as in polyethylene. Elastic modulus of crystalline regions in the direction parallel to the chain axis have since also been measured experimentally using X-ray diffraction (Table 1), providing great insight into the potential of certain polymers to generate high performance fibers [29-31].

Table 1. Theoretical crystal modulus of polymers derived from X-ray diffraction studies [29-31].

\begin{tabular}{cc}
\hline Polymer & Theoretical modulus (GPa) \\
\hline Polyethylene (PE) & 235 \\
Poly(vinyl alcohol) (PVA) & 250 \\
Polyamide-6 (PA 6) & 157 \\
Poly(ethylene terephthalate) (PET) & 108 \\
Polypropylene (PP) & 40 \\
Polyacrylonitrile (PAN) & $35-55$ \\
Thermotropic polyester (Vectran) & 126 \\
Poly(p-phenylene terehthalamide) (PPTA) & 156 \\
Poly(phenylene benzobisoxazole) (PBO) & 478 \\
\hline
\end{tabular}


All the above studies indicated that high modulus and high strength in fibers mainly relies on high polymer chain orientation and extension, combined with sufficient chain length. Inspired by this, polymer scientists have attempted to improve the mechanical properties of fibers by pursuing two routes to reach Staudinger's ideal model, i.e., flexible chain polymers and rigid chain polymers [32].

\subsection{High Performance Fibers Based on Flexible Polymer Chains}

In the case of flexible chains, notably polyethylene, the chains tend to fold upon crystallization and in order to get the desired level of chain extension necessary to exploit the intrinsic properties of the polymer chain, solid-state drawing at elevated temperature but below the melting temperature is applied [33-35]. Great efforts have been devoted to melt-spinning and later also solution-spinning of polyethylene in the 1970s. Ward et al. [36,37] developed polyethylene fibers using a process of melt-spinning followed by drawing in the solid state. This technique had limitations with respect to the use of high molecular weight polymers and as such the tenacity of the obtained fibers, as spinnability (as a result of the rapidly increasing melt viscosity) and fiber drawability both decreased with increasing molecular weight. An initial breakthrough in the development of high strength polyethylene fibers was the so-called surface growth technique from Zwijnenberg and Pennings [38,39]. Here, Young's moduli exceeding $100 \mathrm{GPa}$ and tensile strengths over $3 \mathrm{GPa}$ were obtained from ultra-high molecular weight polyethylene. Their results were a break-through as this was the first experimental evidence that high modulus and high strength structures could be produced from flexible chain polymers [40].

An industrial breakthrough in the production of high modulus and high strength polymer fibers was achieved by the solution (or gel) spinning process developed at DSM in the Netherlands at the end of the 1970s. Smith and Lemstra [41-44] discovered that as-spun ultra-high molecular weight polyethylene filaments from solution could be hot-stretched in the solid-state below the melting temperature to very high draw ratios. In the gel-spinning process, a semi-diluted ultra-high molecular weight (Mw $>10^{6} \mathrm{~g} / \mathrm{mol}$ ) polyethylene solution of low polymer concentration is squeezed through a spinneret and after quenching in a water bath a gel-like filament is obtained (Figure 2). This results in a morphology with a low entanglement density of polymer chains in the as-spun gel-like fiber, which renders them super-drawable.

Figure 2. Schematics of the gel-spinning process [34].

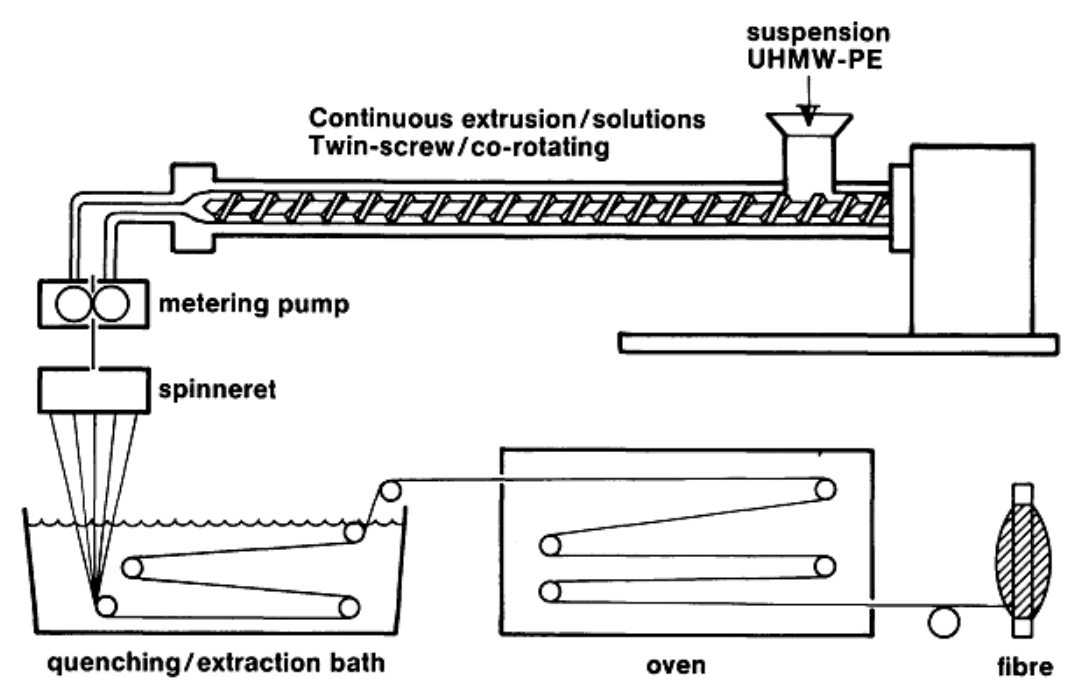


Upon solid-state drawing, the lamellae structure of the as-spun polyethylene fiber will initially orient in the drawing direction. At higher draw-ratios, these lamellae ideally unravel into chain-extended structures approaching ultimate properties (see Table 1). In fact, the solid-state drawing step can be regarded as the single most important process step needed to create high performance fibers, based on flexible chain polymers. Since the relaxation times of flexible chain polymers are typically very short, the elongation flow induced orientation in the as-spun fibers rapidly disappears due to relaxation before solidification. High performance fibers based on flexible chain polymers are therefore typically post-drawn in the solid-state below the melting temperature as this will prevent chain relaxation after orientation and chain extension.

Dyneema $^{\circledR}$ by DSM and Spectra ${ }^{\circledR}$ by its licensee Allied Signal (now Honeywell) are two commercially available high strength and high modulus fibers that use ultra-high molecular weight polyethylene (UHMWPE) as a starting material. These fibers have Young's moduli exceeding 100 GPa and tensile strengths of more than $3 \mathrm{GPa}$, i.e., 100 times that of bulk polyethylene. In combination with their low density $\left(<1000 \mathrm{~kg} / \mathrm{m}^{3}\right)$, this leads to exceptionally high specific mechanical properties (properties per unit weight), making these UHMWPE fibers of interest for a wide range of applications ranging from maritime ropes to protective gloves, bullet-proof vests, and other advanced composites applications.

\subsection{High Performance Fibers Based on Rigid Polymer Chains}

The discovery of rigid rod polymers to produce high performance fibers originated from the discovery of para-oriented aromatic polyamide [45,46], notably, poly( $p$-phenylene terehthalamide) (PPTA). Large research efforts led to significant advances in the fundamental understanding of PPTA polymerization [47], spinning solutions [48,49], spinning process and the structure of para-aramid fibers [48,50], taking full advantage of its rigid rod like molecular structure and unique liquid crystalline properties.

Generally, PPTA exhibits lyotropic liquid crystalline properties in proper solvents, viz. concentrated sulphuric acid. At low concentrations, the rod-like molecules are randomly distributed but they tend to order and form nematic domains above a certain concentration (see also Section 3.3.1.). As chain extension in rigid chains is already built in by the chemist, it is not essential to post-draw these as-spun filaments, which is the main difference between processing fibers based on rigid and flexible chain molecules.

The melting point of PPTA is higher than its degradation temperature, so melt-spinning is not feasible in the case of PPTA. Dry-jet (air gap) wet spinning [47] was utilized as a novel spinning route for these materials in the 1970s. Anisotropic solutions with concentrations of around 19-20 PPTA in concentrated sulphuric acid at $70-90{ }^{\circ} \mathrm{C}$, i.e., concentrated solutions of moderate viscosities, were used for spinning of these fibers. Orientation with extended chain configuration of the liquid crystalline domains is achieved in the air-gap (Figure 3) and fixed in the coagulation bath usually made up of water or diluted sulphuric acid with temperatures in the range of $0-5{ }^{\circ} \mathrm{C}$. The as-spun fibers are then washed, neutralized, and dried afterwards. The degree of chain orientation and crystallinity can be further tuned by changing the draw ratio during spinning and/or by heat treatments. 
Figure 3. Molecular orientation during dry-jet wet spinning of PPTA.

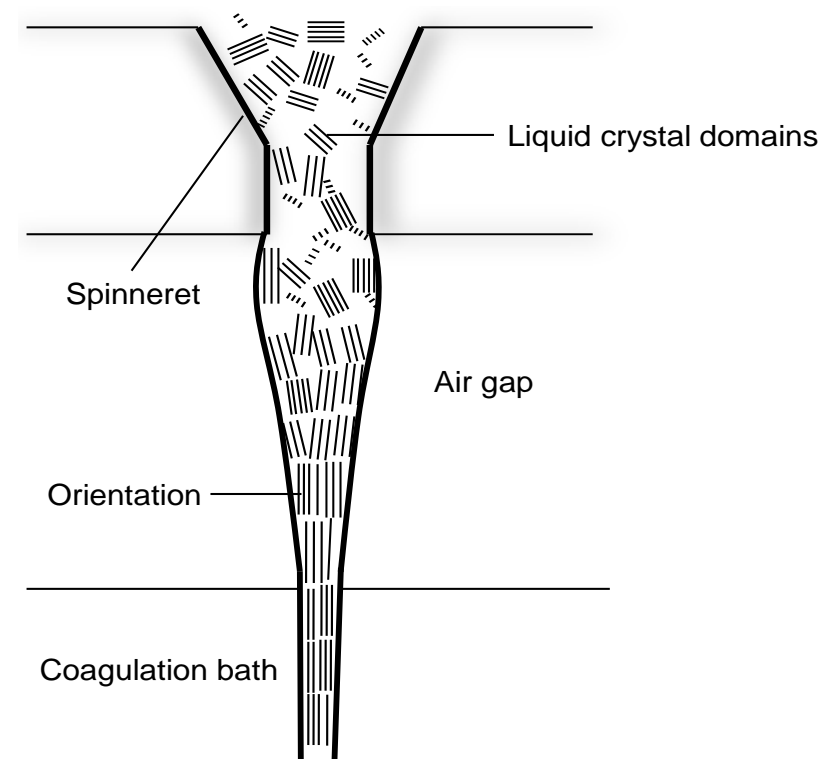

Para-aramid fibers are manufactured under the trademark of Kevlar ${ }^{\circledR}$ (Du Pont, Wilmington, USA) and Twaron $^{\circledR}$ (Teijin Aramid, Arnhem, The Netherlands). A combination of properties like light weight, high strength, high modulus, excellent high temperature resistance and good resistance to chemicals, make para-aramid fibers of interest for aerospace composites, anti-ballistic materials, and many other advanced applications.

Another high strength and high modulus fiber based on (semi) rigid polymer chains is aromatic polyester which exhibits liquid crystalline properties. This thermoptropic liquid crystalline polymer (TLCP) fiber was initially developed by Celanese Corporation and became commercially available in the mid-1980s under the trade name Vectran ${ }^{\circledR}$. Melt-spinning using conventional extrusion practices in combination with moderate draw-down is performed on these thermotropic liquid crystal polyesters to fully exploit its liquid crystalline properties [51].

Other more recent developments in high performance fibers based on lyotropic liquid crystalline rigid rod polymers are poly(phenylene benzobisoxazole) (PBO) from Toyobo Corporation under the trade name Zylon ${ }^{\circledR}$ [52-54] and poly(hydroquinone-diimidazopyridine) (“M-5”) [55] from Akzo-Nobel with a very similar chemical structure as PBO but exhibiting much better compressive properties [56]. The mechanical properties of all these fibers are later shown in Figure 21.

\section{Electrospun Nanofibers}

\subsection{Basic Concepts of Electrospinning}

Electrospinning is a versatile technique that makes use of an -in principle- very simple experimental set-up. Normally, polymers or polymer mixtures to be used in electrospinning are dissolved in organic solvents to make homogenous spinnable solutions. These spinning solutions are usually pumped from a single nozzle at a controlled feeding rate. 10-50 kV DC high voltages are typically applied between two electrodes within a distance of $10-30 \mathrm{~cm}$ to generate an electrostatic field. Consequently, a pending droplet will be stretched to a Taylor cone first by electrostatic repulsion forces resulting 
from charges on the solution [57]. A solution jet will be ejected from the deformed cone when the repulsion force exceeds the surface tension of the pending droplet. In its flight to the counter electrode, it will move in a straight line for a short distance followed by a whipping path (Figure 4) accompanied with solvent evaporation and jet stretching until a solid nanofiber mat (Figure 5) is collected on the substrate.

Figure 4. A typical electrospinning set-up with a grounded collector.

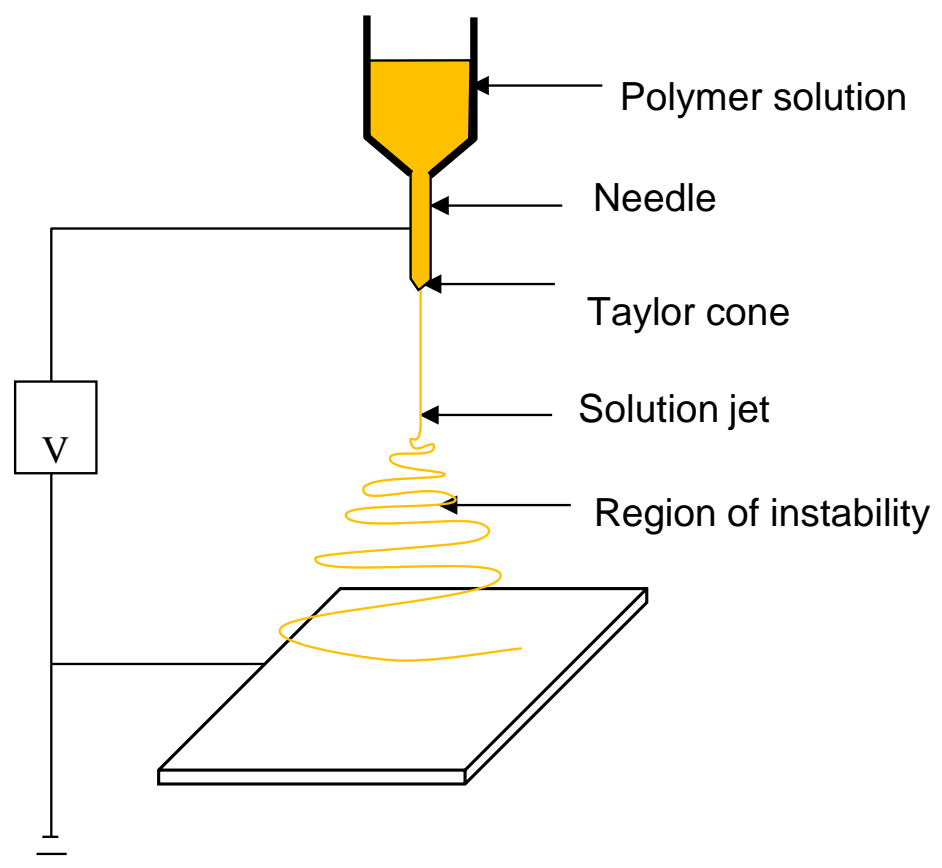

Figure 5. Two scanning electron microscope (SEM) pictures of an electrospun PA6 nanofiber non-woven mat under different magnifications (scale bars of $40 \mu \mathrm{m}$ and $5 \mu \mathrm{m}$, respectively).
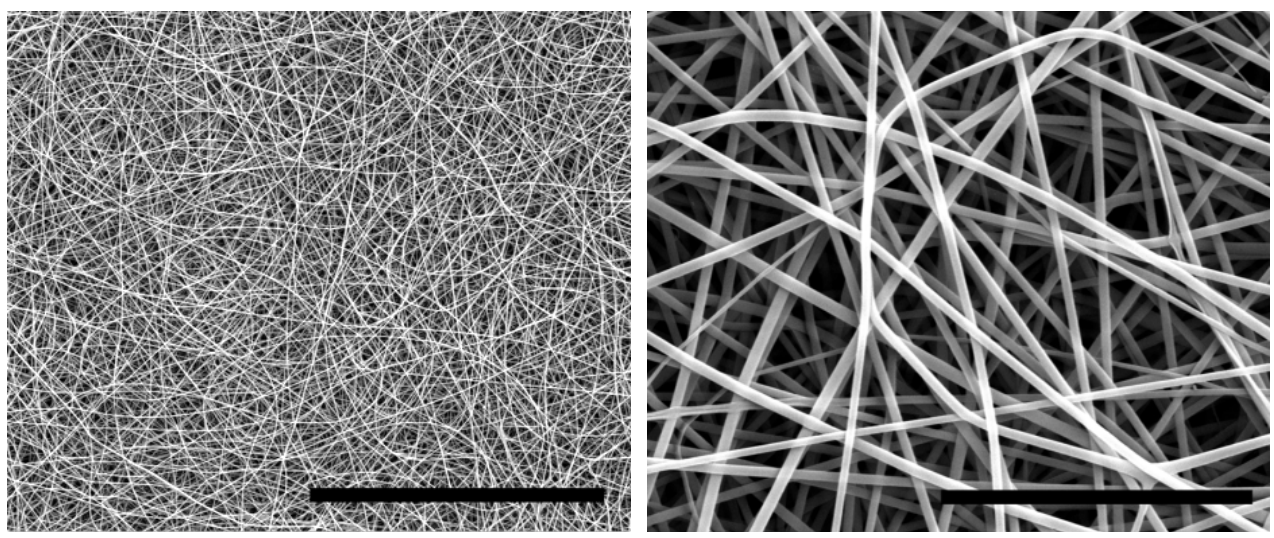

In principle, a numbers of parameters, which can be classified into solution and processing parameters, are believed to affect the electrospinning process. Solution parameters include viscosity (Figure 6), molecular weight of polymer, conductivity, surface tension, etc. Solution feeding rate, process temperature and humidity, applied voltage, distance between electrodes, and design of collector are typical processing parameters which also influence spinnability and fiber morphology [58]. 
A significant disadvantage of electrospinning as a means to create polymer nanofibers has been the low production rate using single needle systems, which have been typically restricted to a few grams per hour. However, recently, several new technologies have been suggested that tackle this issue.

Free liquid surface electrospinning [59] such as the Nanospider ${ }^{\circledR}$ technology applies a nozzle-less electrospinning head instead of a traditional nozzle based set-up. Its rotating electrospinning head can carry a thin layer of polymer solution from a liquid polymer bath and nanofiber layers in a high throughout rate can be produced when the polymer solution is exposed to a high electrical field (Figure 7a). Electrospinning has also been combined with traditional polymer processing techniques such as twin-screw extrusion in order to improve the ability to spin more viscous systems including polymer melts [60]. Moreover, such a process can generate high production rates when combined with multi-nozzle spinnerets (Figure 7b) [61].

Figure 6. Different fiber morphologies of electrospun nanofibers produced from low solution concentration to high solution concentration of poly(methyl methacrylate) (PMMA) in DMF.
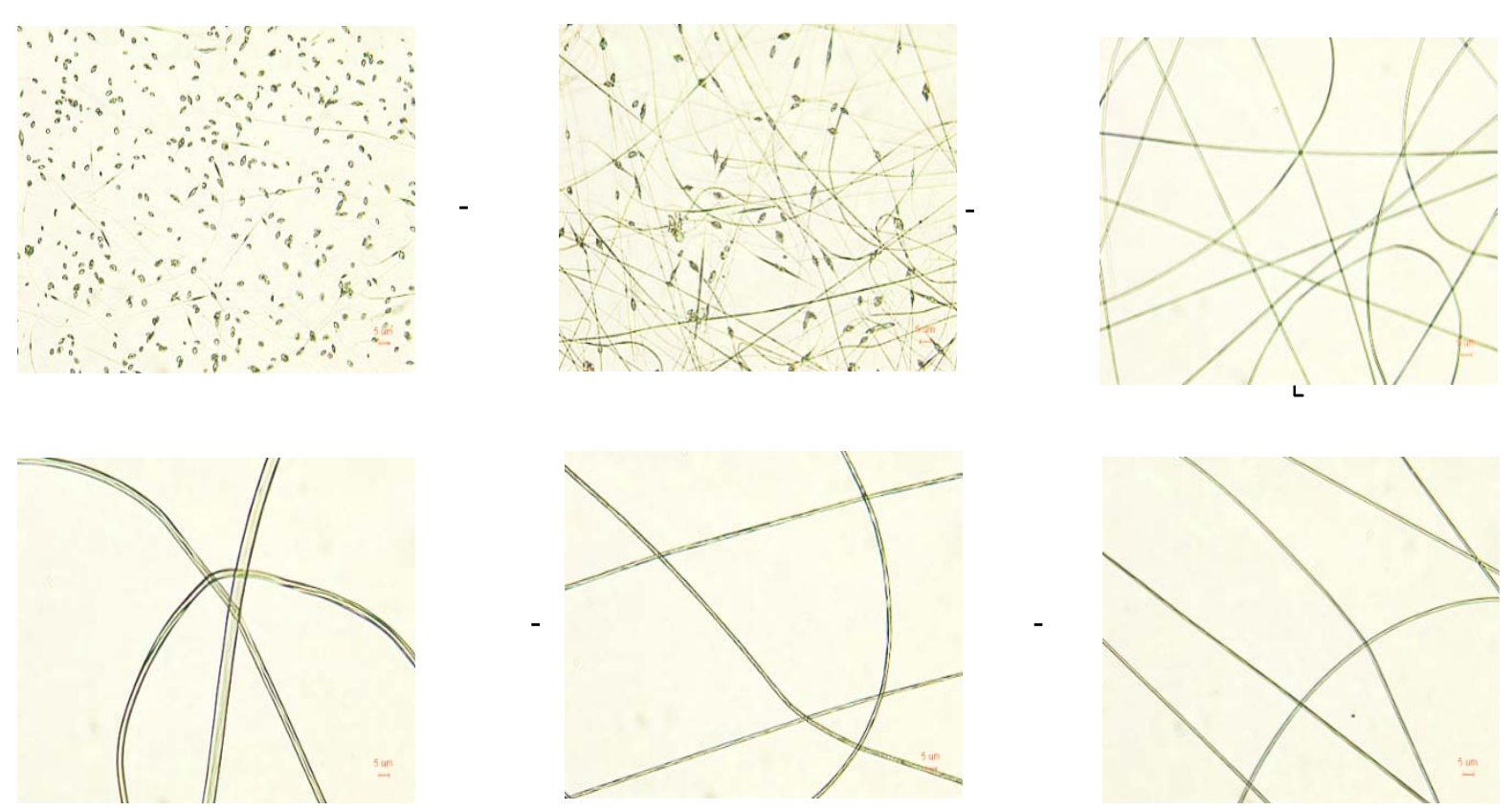

Recently also alternative spinning technologies for nanofibers have been introduced, such as a rotary jet-spinning technology that is capable of high rate spinning [62]. Unlike conventional electrospinning using an electrostatic force as driving force to generate fibers, in rotary jet-spinning nanofibers are fabricated by a centrifugal force caused by high speed rotation of a polymer solution or melt as shown in Figure 7c.

To make high performance electrospun nanofibers, in principle, the molecular structures of nanofibers should be oriented with chain extension, and should resemble the ideal polymer chains model described in Figure 1. In the next section, recent reports on mechanical properties of electrospun nanofibers are presented according to their intrinsic chain flexibility, viz. flexible chains versus rigid chains. Some nanofibers possessing enhanced mechanical properties are highlighted. 
Figure 7. Novel nanofiber production technologies (a) nozzle-less electrospinning with a rotating head [59]. Reproduced with permission from Petrik et al., 2009. Copyright Cambridge Univ Press. (b) Multi-nozzle electrospinning with a twin-screw extrusion [61]. Reproduced with permission from Senturk-Ozer et al., 2012. Copyright John Wiley \& Sons. (c) Rotary jet-spinning [62]. Reproduced with permission from Badrossamay et al., 2010. Copyright American Chemical Society.

(a)

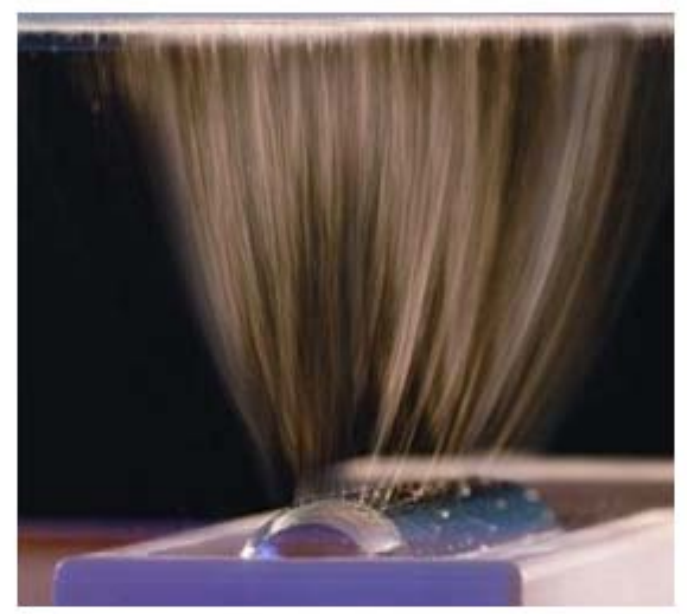

(b)

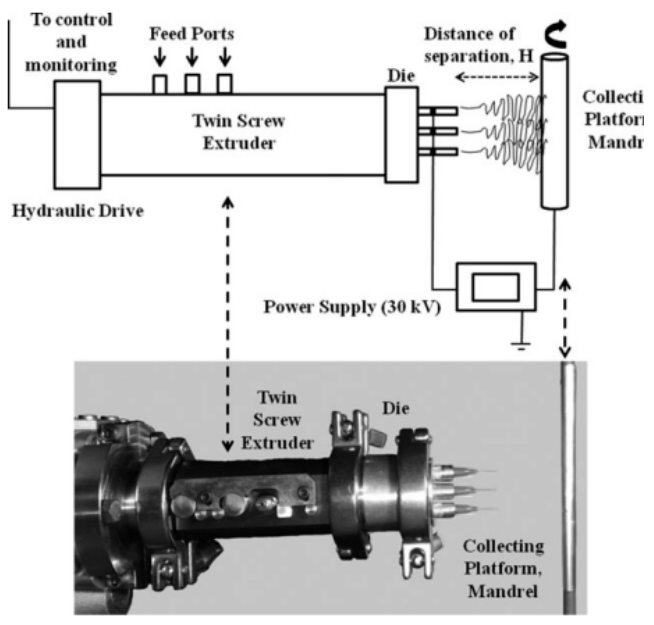

(c)

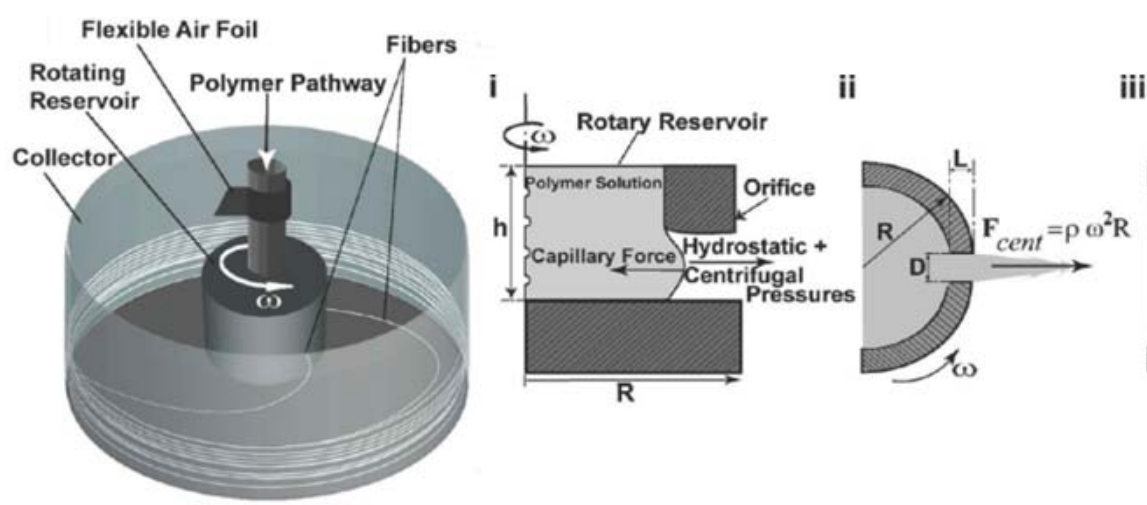

iii

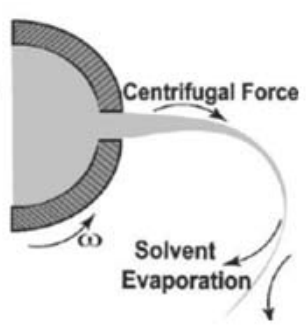

\subsection{Electrospun Nanofibers Based on Flexible Chain Polymers}

Inspired by the success of Dyneema ${ }^{\circledR}$, Rein et al. [63] tried to fabricate UHMWPE fibers using the electrospinning method. The mechanical properties of manually twisted yarn from as-spun nanofiber mats were investigated and a tensile strength of $129 \mathrm{MPa}$ and modulus of $0.4 \mathrm{GPa}$ were reported, which are well below those of commercial UHMWPE fibers at around $3000 \mathrm{MPa}$ and 100 GPa, respectively [64]. The relatively low strength and modulus of these electrospun UHMWPE fibers can to some extent be explained from their wide-angle X-ray scattering (WAXS) pattern (Figure 8). The WAXS data shows a significant difference of the average molecular chain orientation in electrospun and solution-spun ultra-drawn UHMWPE. Where electrospun UHMWPE shows broad (110) and (200) reflection arcs, shows only ultra-drawn UHMWPE greatly intensified reflections typical of a highly oriented polymer fiber. 
Figure 8. (a) WAXS pattern of electrospun UHMWPE nanofiber [63], showing broad reflection arcs typical of a moderately oriented polymer structure. Reproduced with permission from Rein et al., 2007. Copyright John Wiley \& Sons. (b) WAXS pattern of solution-spun ultra-drawn UHMWPE fiber with draw-ratio 100, showing intense reflections typical of a highly oriented polymer structure [33].

(a)

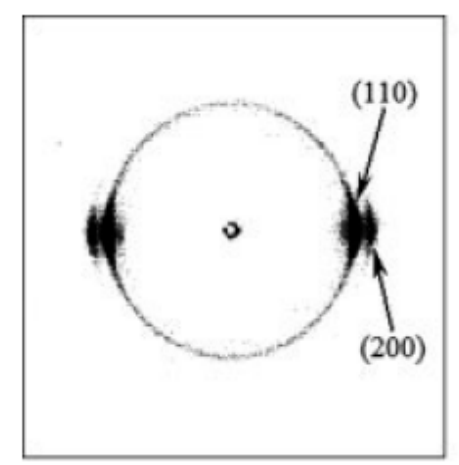

(b)

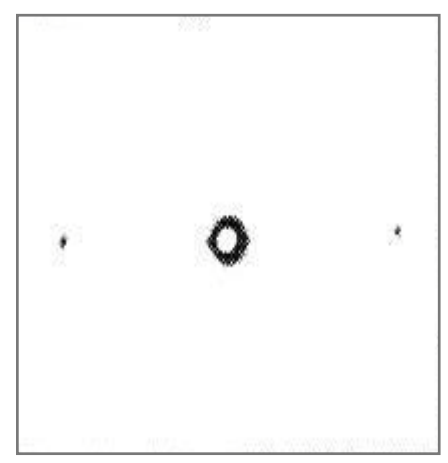

Table 2. Mechanical properties of electrospun polyamide (PA) and poly(ethylene terephthalate) (PET) nanofibers.

\begin{tabular}{|c|c|c|c|c|c|}
\hline Polymer & Solvent \& concentration & Sample & $\begin{array}{l}\text { Modulus } \\
\text { (MPa) }\end{array}$ & $\begin{array}{l}\text { Strength } \\
\text { (MPa) }\end{array}$ & Refs. \\
\hline PA 6 & $\begin{array}{c}6 \text { wt } \% \text { in } 1,1,1,3,3,3- \\
\text { hexafluoro-2- propanol }\end{array}$ & $\begin{array}{c}\text { Nonwoven } \\
\text { nanofiber mat }\end{array}$ & $34 \pm 2$ & $7.2 \pm 0.5$ & \multirow{2}{*}[65]{} \\
\hline PA 6,6 & $\begin{array}{l}7.5 \mathrm{wt} \% \text { in 1,1,1,3,3,3- } \\
\text { hexafluoro-2-propanol }\end{array}$ & $\begin{array}{c}\text { Nonwoven } \\
\text { nanofiber mat }\end{array}$ & $21 \pm 1$ & $6.5 \pm 0.8$ & \\
\hline \multirow[t]{2}{*}{ PA 6} & \multirow[t]{2}{*}{$20 \mathrm{wt} \%$ in formic acid } & $\begin{array}{c}\text { Nonwoven } \\
\text { nanofiber mat }\end{array}$ & 19 & 10.5 & \multirow[t]{2}{*}[66]{} \\
\hline & & Single nanofiber & 902 & 304 & \\
\hline PA 6,6 & $20 \mathrm{wt} \%$ in formic acid & Single nanofiber & $950 \pm 390$ & $150 \pm 49$ & {$[67]$} \\
\hline PA 6,6 & $\begin{array}{l}10 \mathrm{wt} \% \text { in formic acid \& } \\
\text { chloroform }(75: 25 \mathrm{v} / \mathrm{v})\end{array}$ & Nanofiber yarn & 1216 & 120 & {$[68]$} \\
\hline PA 6 & $\begin{array}{l}12 \mathrm{wt} \% \text { in formic acid \& } \\
\text { acetic acid }(50: 50 \mathrm{w} / \mathrm{w})\end{array}$ & Single nanofiber & $1320 \pm 152$ & $78.1 \pm 6.0$ & [69] \\
\hline PA 6 & $\begin{array}{l}12 \mathrm{wt} \% \text { in formic acid \& } \\
\text { acetic acid }(50: 50 \mathrm{w} / \mathrm{w})\end{array}$ & $\begin{array}{c}\text { Nonwoven } \\
\text { nanofiber mat }\end{array}$ & $418 \pm 93$ & $57.7 \pm 8.9$ & {$[70]$} \\
\hline PET & $\begin{array}{c}30 \%(w / v) \text { in TFA \& DCM } \\
(70: 30 \mathrm{v} / \mathrm{v})\end{array}$ & $\begin{array}{c}\text { Nonwoven } \\
\text { nanofiber mat }\end{array}$ & 60 & 3.7 & {$[71]$} \\
\hline PA 6/6,6 & Melt & Bulk & $2000-2500$ & $50-80$ & \multirow{2}{*}[23]{} \\
\hline PET & Melt & Bulk & 2000-3000 & 50-150 & \\
\hline PA 6/6,6 & Melt-spun + drawn & Single fiber & 6000 & 1000 & \multirow{2}{*}[40]{} \\
\hline PET & Melt-spun + drawn & Single fiber & 15000 & 1100 & \\
\hline
\end{tabular}

With respect to the vast amount of research on other electrospun nanofibers based on flexible chain polymers such as aliphatic polyamide and polyester, a relatively limited number of studies involved the 
mechanical properties of non-woven nanofiber mats or even single nanofibers. According to Table 2, the mechanical properties of most electrospun polyamide and polyester fibers are also not comparable with conventional microfibers manufactured by melt-spinning, which again can be ascribed to the low degree of chain orientation in these as-spun nanofibers and the absence of a post-drawing step in the electrospinning process. In fact, in many cases the properties of electrospun fiber properties are even inferior to that of the bulk polymer, which can be attributed to factors, such as residual solvent, plasticization, and porosity.

Although traditional methods to induce high molecular orientation like post-drawing are usually not feasible for single nanofibers, at least for the time being due to technological difficulties, limited stretching or drawing has been attempted to oriented nanofiber mats in order to generate improved molecular orientation and crystallinity. Zong et al. [72] stretched PLGA nanofiber membranes up to a deformation of $450 \%$ at $90{ }^{\circ} \mathrm{C}$. An improvement in mechanical properties after post-drawing was observed as seen in Figure 9, although the properties achieved remained low. Wu et al. [73] also tried solid-state hot-drawing at $135{ }^{\circ} \mathrm{C}$ of polyacrylonitrile (PAN) nanofiber sheets. Here, the crystallinity increased from $7.9 \%$ for as-spun nanofiber mats to $31.8 \%$ for hot-drawn mats, while the tensile strength was raised from $100 \mathrm{MPa}$ to $220 \mathrm{MPa}$, correspondingly.

Kongkhlang et al. [74] attempted to induce favorable orientation and increased crystallinity directly into as-spun electrospun nanofibers using a high-speed collector for nanofibers collection. Figure 10 exhibits two 2D wide-angle X-ray diffraction patterns of polyoxymethylene (POM) nanofibers electrospun with different take up speeds. It is clearly shown that a higher collecting speed of $1890 \mathrm{~m} / \mathrm{min}$ induces a higher degree of orientation in these nanofibers. In addition, it should be noted that alignment of the nanofibers within the mat is also vital for achieving high strength and high modulus structures as misalignment will significantly reduce the efficiency of the fibers within a mat and will greatly reduce its mechanical properties [75].

Figure 9. Strain-stress curves electrospun poly(glycolide-co-lactide) (PLGA) of as-spun nanofiber mat and nanofiber mat after a solid-state deformation of 450\% [72]. Reproduced with permission from Zong et al., 2003. Copyright Elsevier Publisher.

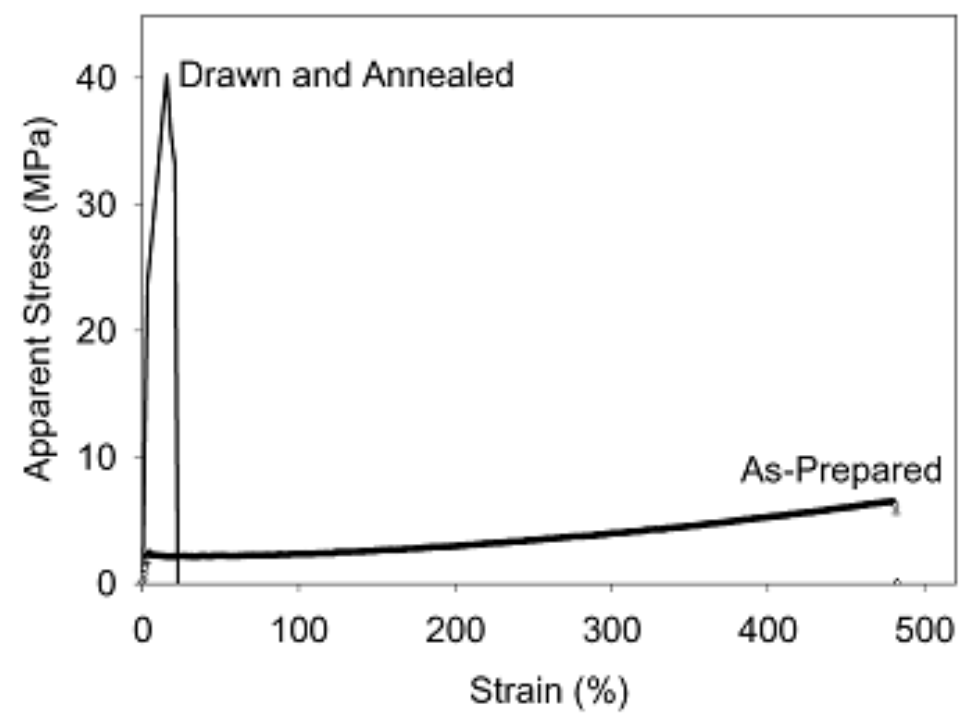


Figure 10. Two dimensional (2D) wide-angle X-ray diffraction patterns of electrospun polyoxymethylene (POM) nanofibers with different take up speeds (a) $630 \mathrm{~m} / \mathrm{min}$ (b) $1890 \mathrm{~m} / \mathrm{min}$ [74]. Reproduced with permission from Kongkhlang et al., 2008. Copyright Americal Chemical Society.
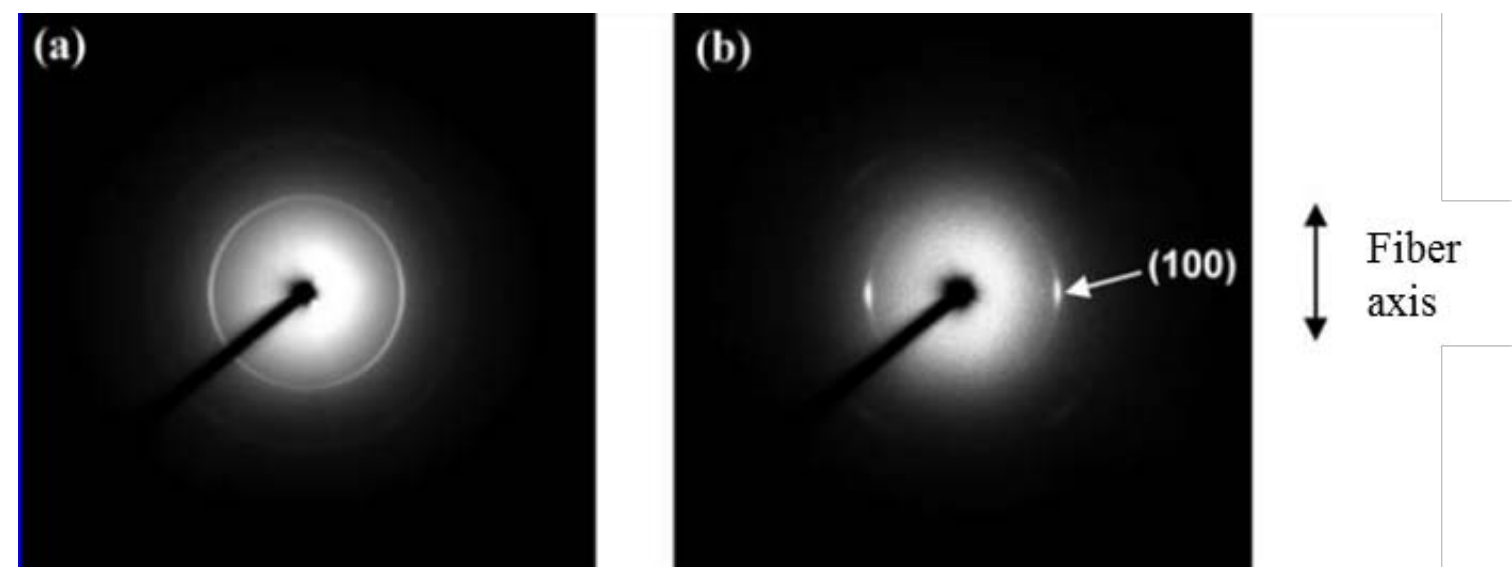

Although it has been shown by various researchers that electrospinning can induce some level of chain orientation in fibers based on flexible chain polymers, these levels are often rather low. An interesting study in this respect was by Mohan et al. [76]. Here, small angle neutron scattering (SANS) was used to quantify the size and shape of the chain conformation in electrospun fibers of deuterated atactic polystyrene prepared from solutions. Although the orientation parameter $\left\langle\mathrm{P}_{2}\right\rangle$ was found to increase with increasing collecting speed, the maximum value of about 0.15 (Figure 11a) was well below the orientation parameter expected for high performance polymer fibers with values typically approaching 1 . When the tangential velocity of the rotating collector was greater than the flight velocity of the fibers some degree of orientation of the polymer coils was induced. However, even at the highest collector speeds the ratio of the radii of gyration increased only by $20 \%$ from for bulk (17 nm) to fibers $(20 \mathrm{~nm})$, showing limited coil deformation. As the diameters of these fibers was much greater than the polystyrene radius of gyration these effects can be solely contributed to flow-induced orientation, excluding size or confinement effects as a result of nanosized fiber diameters.

The influence of size effects on the mechanical properties of electrospun fibers has been studied extensively [77-83] with many studies showing an increase in Young's modulus with decreasing nanofiber diameter. In most cases it is assumed that such an increase is due to confinement of the polymer coils as they are forced to align along the nanofiber axis. Confinement effects are regarded by most researchers as the main reason for property improvement in electrospun nanofibers. However, although some degree of alignment and orientation can be envisaged with decreasing fiber diameter, particularly if the diameter is reduced to below the coil size, full chain extension as observed in super-drawn high performance fibers will be more difficult to achieve.

Nevertheless, a certain degree of orientation of polymer chains has been observed in electrospun fibers when their diameter is decreased. Figure 12a shows improved crystalline and extended amorphous structures in polycaprolactone (PCL) nanofibers for two diameters of $150 \mathrm{~nm}$ and $450 \mathrm{~nm}$, produced under similar conditions [78]. Although an increase in mechanical properties with decreasing fiber diameter was reported for these PCL fibers the maximum reported Young's modulus remained 
low at 2 GPa. Additionally, chain orientation has also been observed in nanofibers that showed birefringence under crossed polarizers [8,84].

Figure 11. (a) Orientation parameter $<\mathrm{P}_{2}>$ obtained from SANS experiments for as-spun polystyrene fibers as a function of collector speed. Red circles represent uncorrected data for fiber angular alignment on the electrode while black squares are corrected data. Open symbols represent samples collected on static parallel plate electrode. (b) Radius of gyration of the polymer chains parallel (black squares) and perpendicular (red circles) to the fiber direction together with bulk data (dashed line) [76]. Reproduced with permission from Mohan et al., 2011. Copyright Royal Society of Chemistry.
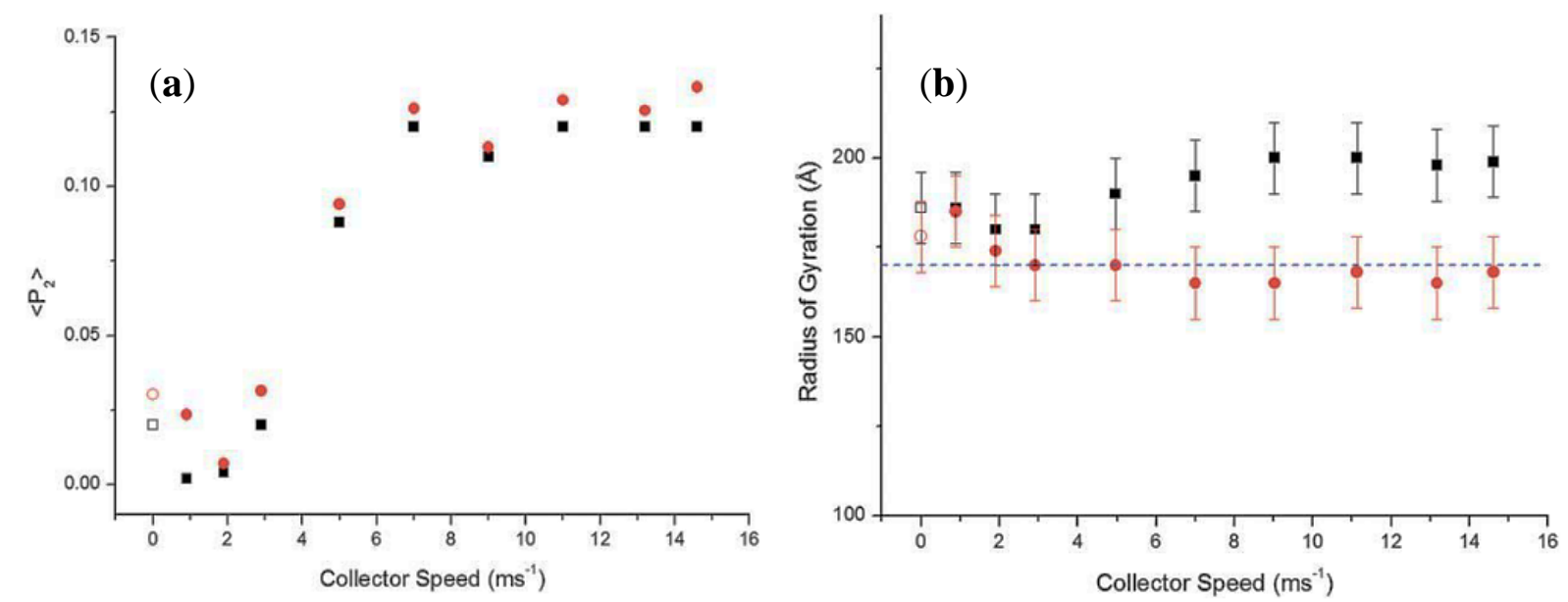

Figure 12. PCL nanofibers produced under similar conditions but with different fiber diameters (a) $150 \mathrm{~nm}$ (b) $450 \mathrm{~nm}$, showing a thinner nanofiber possessing a more aligned fibrillar and lamellae microstructure [78]. Reproduced with permission from Lim et al., 2008. Copyright AIP Publisher.
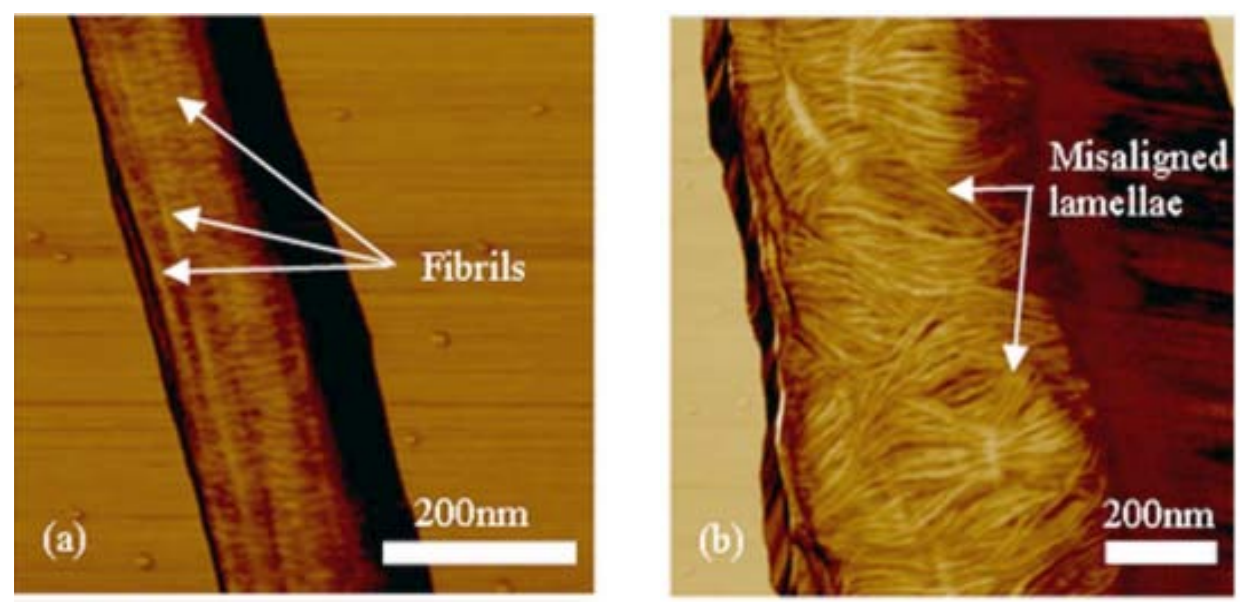

Stachewicz et al. [85] found that electrospun PVA nanofibers can possess a composite-like core-shell structure, with the shell region being aligned as a result of rapid solvent evaporation suppressing chain relaxation, and the core region being isotropic. This core-shell structure is used to explain the increase in elastic modulus with decreasing PVA nanofiber diameter as the shell component remained fairly constant at around $30 \mathrm{~nm}$, meaning that the relative contribution of the 
shell region increases with decreasing fiber diameter. Properties of these PVA fibers indicated an increase in elastic modulus, as measured by single fiber AFM bending tests, for diameters below $300 \mathrm{~nm}$. Elastic moduli up to $13 \mathrm{GPa}$, six times that of bulk PVA, were reported for fibers with diameters just below $100 \mathrm{~nm}$. Although these values are superior to most reported data for electrospun fibers these values still do not rival solid-state drawn solution-spun PVA fibers possessing Young's moduli up to $70 \mathrm{GPa}$ and tensile strengths of approximately $2 \mathrm{GPa}$ [86].

Arinstein et al. [87] related the size of oriented regions in electrospun nylon 6,6 nanofibers to the rapid increase in Young's modulus and quantified the percolation of the cross-section area required by using a modified Onsager model. A value of about $300 \mathrm{~nm}$ for a critical fiber diameter was found, below which a rapid increase in Young's modulus is initiated. Arinstein et al. [88] also reported an increase in Young's modulus in electrospun nylon 6,6 nanofibers with decreasing fiber diameter (Figure 13). Here the authors suggest that the rapid increase in Young's modulus with decreasing fiber diameter is not the result of the small increase in observed crystallinity or orientation of the crystallites. Instead they ascribed the increase in mechanical properties to orientation of amorphous regions when their sizes are comparable or smaller than the nanofiber diameter.

Figure 13. Relative Young's modulus $E_{\text {rel }}\left(E_{\text {rel }}=E / E_{\text {bulk }}\right)$ of electrospun PA 6,6 nanofibers as a function of their diameters [88]. Reproduced with permission from Arinstein et al., 2007. Copyright Nature Publisher.

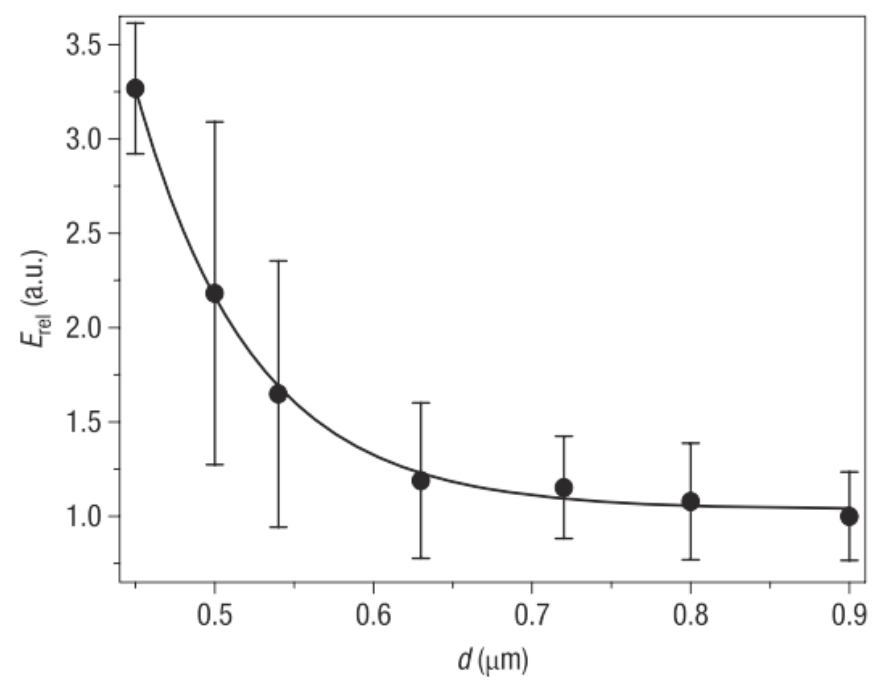

Most studies show similar to results reported by Arinstein et al. [86], i.e., a three-fold increase in Young's modulus of thin electrospun fibers compared to that of bulk polymer. Naraghi et al. reported an increase in Young's modulus for electrospun PAN fibers smaller than $300 \mathrm{~nm}$, with a three-fold increase in modulus for diameters ranging from 100-200 nm [89]. Pai et al. reported a similar increase in Young's modulus of individual electrospun fibers of poly(trimethyl hexamethylene terephthalamide) (PA 6(3)T) [80]. Here, the Young's modulus was found to increase for fibers with diameters smaller than $500 \mathrm{~nm}$, with a maximum modulus value reported of around $6 \mathrm{GPa}$ for $170 \mathrm{~nm}$ fibers, i.e., three times the bulk modulus.

One recent example of a more significant property improvement in electrospun fibers that was ascribed to confinement effects was reported for polyacrylonitrile (PAN). Young's moduli up to 
$48 \mathrm{GPa}$ and tensile strengths up to $1.75 \mathrm{GPa}$ were reported by Dzenis and coworkers [90] for individual PAN nanofibers, approaching typical values for high performance fibers. Unlike traditional high performance fibers, where an increase in mechanical properties is often accompanied with a sacrifice in strain at break, these ultrafine PAN nanofibers were also simultaneously stiff and ductile. The highest value of toughness was achieved from the thinnest electrospun nanofiber with a diameter of $138 \mathrm{~nm}$. Similar to Arinstein et al. their increase in mechanical properties was not ascribed to increased crystallinity (Figure 14) as crystallization was restrained by the fast solidification that resulted from the rapid evaporation of solvent. Again it was proposed that the increase in mechanical properties was mainly related to confined molecular orientation of amorphous regions with decreasing nanofiber diameter.

The mechanical properties of these electrospun PAN fibers are particularly impressive, with the reported Young's modulus of $48 \mathrm{GPa}$ approaching or even exceeding theoretical values for atactic PAN (55 GPa) [91] or isotactic PAN having a 3/1 helical conformation (35 GPa) [91], although theoretical calculations have indicated that the crystal modulus of PAN taking a planar-zigzag conformation could reach values as high as $130 \mathrm{GPa}$ [92]. In contrast to most other electrospun fibers, including PAN, where confinement effects typically result in a moderate increase in modulus $[80,85,87,88]$, here a nanofiber modulus is reported that is $\sim 25$ times greater than that of bulk PAN. This is in stark contrast to studies of Naraghi et al. [89], who reported only a three-fold increase in Young's modulus for electrospun PAN fibers with a maximum value of $7 \mathrm{GPa}$ for a $150 \mathrm{~nm}$ fiber. Similarly, these high performance PAN nanofibers also outperform most conventional wet-spun high strength acrylic fibers with typical Young's moduli of 10-20 GPa and tensile strengths of 1-1.5 GPa [93]. In fact, the values reported for these electrospun PAN fibers exceed those of super-drawn solution-spun ultra-high molecular weight PAN fibers by Kanamoto and co-workers who obtained tensile moduli of $35 \mathrm{GPa}$ and strengths of $1.8 \mathrm{GPa}$ for fibers of draw-ratio 80, exhibiting extremely high levels of chain orientation [92].

Figure 14. (a) Stress-strain curves of electrospun PAN nanofibers with different diameters (b) XRD patterns of nandiber bundles with various fibre diameters and corresponding degree of crystallinity (inset) [90]. Reproduced with permission from Papkov, D. et al., 2013, Copyright American Chemistry Society.
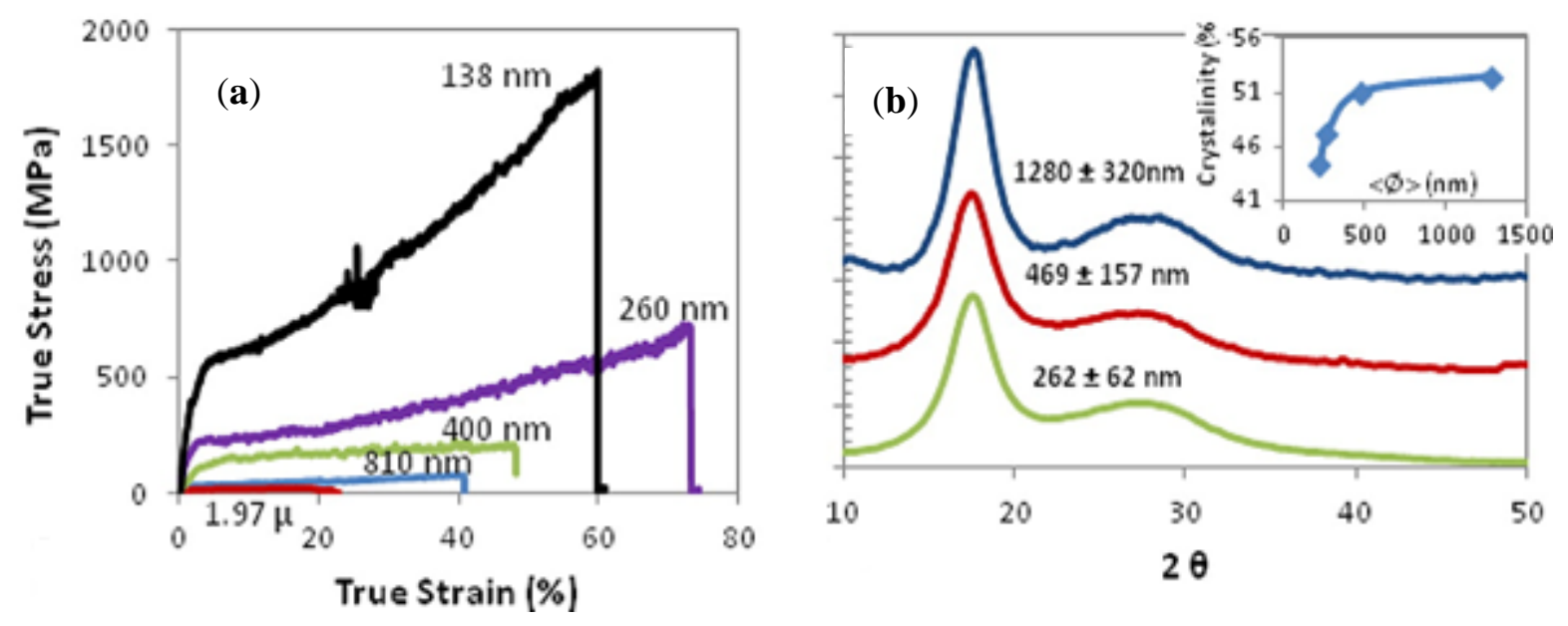
The underlying mechanisms of these exceptional properties are therefore still to be debated. The high modulus of the PAN nanofibers seems not related to their crystallinity as the reported crystallinity $(<50 \%)$ does not significantly increase with decreasing fiber diameter and is also less than that of conventional PAN fiber ( 65\%) [94]. Since flow-induced orientation is difficult to achieve during fiber spinning due to fast chain relaxation, and because these fibers are not post-drawn, it is difficult to envisage higher levels of chain extension in these as-spun nanofibres than in the super-drawn UHMW-PAN fibers by Sawai et al. [92]. Moreover, as the estimated coil size of a PAN molecule with a molar mass of 150,000 is of the order of $30-40 \mathrm{~nm}$ based on its mean square end-to-end distance $\left(<R^{2}>=C_{\infty} n l^{2}\right)[95,96]$ it is also difficult to imagine the extreme confinement effects in $138 \mathrm{~nm}$ fibers which are necessary to explain such property improvement. Nevertheless, the reported mechanical properties of these electrospun PAN fibers are very interesting and require further studies.

In summary, the relatively poor mechanical properties of flexible chain based polymer nanofibers are mainly ascribed to two phenomena. The first one is related to the relatively low degree of chain orientation in these systems. Orientation of macromolecules can be usually introduced from a random coil morphology when the product of the polymer chain relaxation time and the strain rate in the electrospinning process is greater than 0.5 [57]. Given that strain rates can be up to $10^{5} \mathrm{~s}^{-1}$ while viscoelastic relaxation times are found to be tens to hundreds of milliseconds [97,98], some level of chain orientation can be potentially generated. However, residual solvents in the deposited nanofibers can accelerate chain relaxation and lead to shorter relaxation times [57]. Hence, relaxation of polymer chains could be suppressed by rapid solvent evaporation and fiber solidification [58]. As relaxation times of flexible chain polymers are typically very short, orientation induced in the initial spinning process may rapidly disappear before solidification. It is for this reason that conventional high performance fibers based on flexible chain polymers are post-drawn in the solid state below the melting temperature as this will prevent chain relaxation after orientation. Similarly, low degrees of molecular orientation are to be expected in electrospun fibers based on flexible chain polymers, explaining their poor mechanical properties. Nonetheless, the mechanics in achieving chain orientation in electrospun fibers is still controversial due to the lack of systematically studies. For instant, most of characterizations on molecular orientation and mechanical properties in electrospun nanofibers are conducted on nanofiber mats or bundles rather than single fibers [99]. Therefore, in future research more attentions should be paid to single fiber characterization in order to establish better structure-processing-property relationships.

The second reason for the relatively poor mechanical properties of electrospun fibers is that full chain extension is nearly impossible to realize during the electrospinning process in the case of flexible chain polymers, which is crucial for obtaining a high performance fiber with properties approaching the theoretical crystal moduli listed in Table 1. With the exception Dzenis and co-workers' PAN nanofiber [90], the differences between experimentally reported Young's moduli of electrospun nanofibers and these ultimate values are very large. Assuming the hypothetical case that polymer chain extension from random coil morphology is induced by virtue of reducing the nanofiber diameter to the same level as the size of crystallites or even the size of a single chain one might envisage a high modulus. Respective average crystallite size and chain size of PA 6,6 are around $4 \mathrm{~nm}$ and $0.1 \mathrm{~nm}$ [87], respectively, and polymer chains could be forced to extent and orient along the fiber axis if fiber diameters would go down to these levels. In such a case the Young's modulus of the fiber would be 
potentially approaching near theoretical values. However, even in such a hypothetical case it is expected that such ultra-thin fibers would be extremely weak as there would be insufficient overlap between chains, resulting in poor stress transfer.

\subsection{Electrospun Nanofibers Based on Rigid Chain Polymers}

\subsubsection{Electrospun PPTA Fibers}

While chain extension in the case of flexible chain polymers can effectively be only achieved by solid-state drawing, the extension of polymer chains can be readily build in by polymer scientists when using rigid rod polymers. Rigid rod polymers have a significant advantage over flexible chain polymers as these systems can be oriented during the spinning process without the need of a post-drawing process to induce chain extension.

Inspired by the success of high performance aramid fibers the electrospinning of poly(p-phenylene terehthalamide (PPTA) and characterization of the obtained nanofiber structures was carried out by Srinivasan and Reneker [100].

In their studies a homogeneous isotropic solution was formed by dissolving PPTA fibers $\left(\right.$ Kevlar $49^{\circledR}$ ) at a concentration of $2-3$ wt\% in a solvent of $95 \%-98 \%$ sulphuric acid. A water bath was used for extracting the solvent and collecting the electrospun nanofibers $12-18 \mathrm{kV}$ high voltages were applied between two electrodes at a distance of $3 \mathrm{~cm}$. Nanofibers with diameters ranging from $40 \mathrm{~nm}$ to hundreds of nanometers were produced (Figure 15). The meridional and equatorial reflection of the as-spun and at $400{ }^{\circ} \mathrm{C}$ annealed PPTA nanofibers were shown in dark field mode transmission electron microscopy (TEM) and revealed some order in the fibers. However, only moderate chain orientation in these annealed PPTA nanofibers was demonstrated using electron diffraction. Moreover, a continuous electrospinning process and mechanical properties of the deposited nanofibers were not reported.

Figure 15. A single electrospun PPTA fiber together with a single $\operatorname{Kevlar}^{\circledR} 49$ fiber [100]. Reproduced with permission from Srinivasan \& Reneker, 1995. Copyright John Wiley \& Sons.

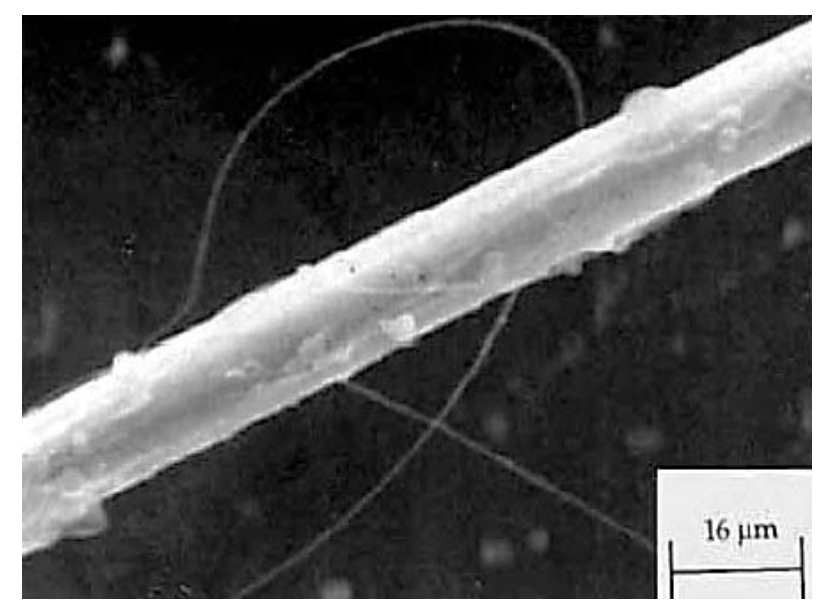

Traditional high performance $p$-aramid fibers are typically produced from anisotropic PPTA solutions with concentrations of around 19-20 wt\% as shown in Figure 16 [94]. However, in the work 
of Srinivasan and Reneker, spinning solutions employed (2-3 wt\% ) were in their isotropic phase, which is outside the regime needed for flow induced molecular orientation as in the case of dry-jet wet spinning of high performance $p$-aramid fibers. Nevertheless, electrospinning of rigid rod polymers like aramids could still show promise once anisotropic PPTA solutions are used under optimized conditions, as it avoids problems related to chain relaxation in as-spun fibers.

Figure 16. Liquid crystalline behavior of PPTA solution, indicating an isotropic phase at concentrations below $12 \mathrm{wt} \%$ and an anisotropic phase between concentrations of $12 \mathrm{wt} \%$ to $20 \mathrm{wt} \%$.

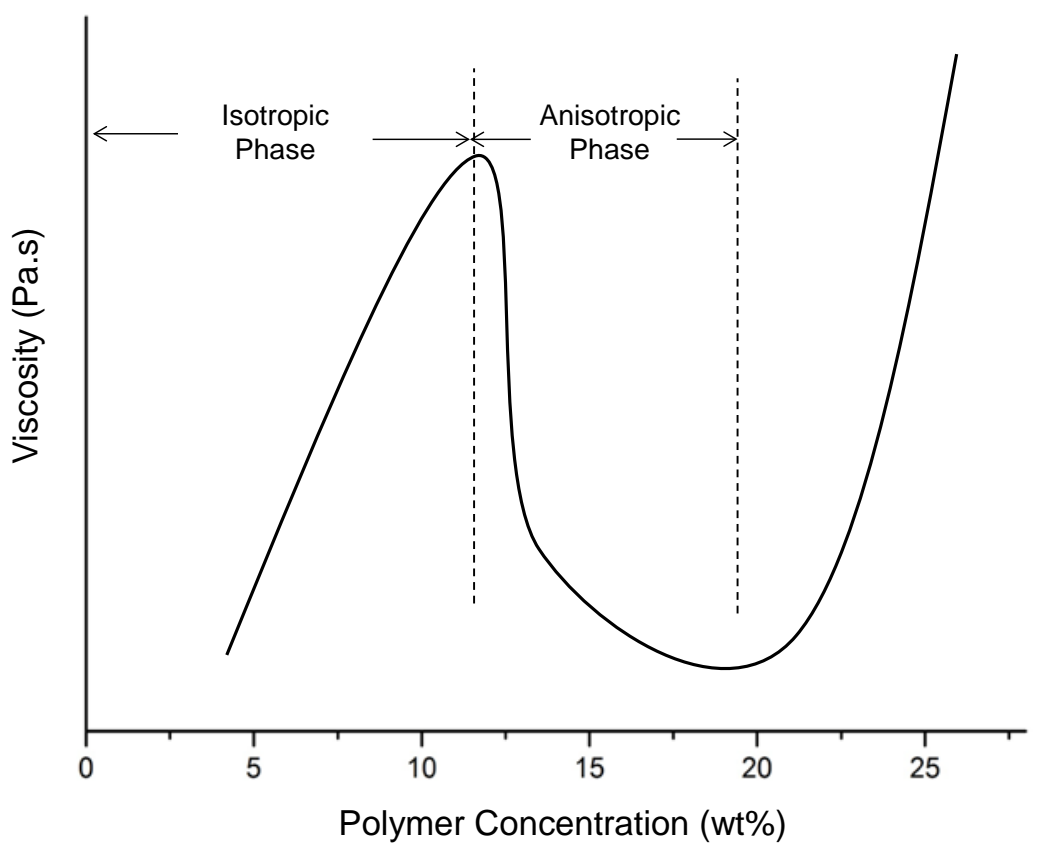

\subsubsection{Electrospun Polyimide Nanofiber}

Poly(p-phenylene biphenyltetracarboxamide) (BPDA/PDA) is a high performance aromatic polyimide with great mechanical properties but a less rigid structure compared to PPTA [75] (Figure 17). Because of the rigid macromolecular backbone, it is insoluble in common organic solvents and thus not directly spinnable from solutions.

However, the precursor of BPDA/PDA, poly( $p$-phenylene biphenyltetracarboxamide acid) (BP-PAA) (Figure 18) shows good solubility in common organic solvents and it is therefore feasible to electrospin BP-PAA precursor fibers and subsequently convert them into BPDA-PDA polyimide nanofibers through a heat treatment.

Hou and coworkers [101,102] investigated the electrospinning process and mechanical properties of these polyimide nanofibers. Under proper spinning condition, a well-aligned BP-PAA nanofiber mat was obtained on a high-speed collector and the aligned polyamic acid nanofiber samples were imidized into polyimide nanofibers. During this imidization process, the rigid-rod molecular chains tend to become oriented and extended along the fiber axis (Figure 18). 
Figure 17. Structural formulas of (a) PPTA and (b) BPDA/PDA polyimide.<smiles>CC1=C(c2ccc(C(=O)Nc3ccc(N(C)C)cc3)cc2)CC1</smiles><smiles>CN1C(=O)c2ccc(-c3ccc4c(c3)C(=O)N(c3ccc(C(C)(C)C)cc3)C4=O)cc2C1=O</smiles>

(a)

Figure 18. A schematic diagram of the imidization process [75]. Reproduced with permission from Huang et al., 2006. Copyright John Wiley \& Sons.

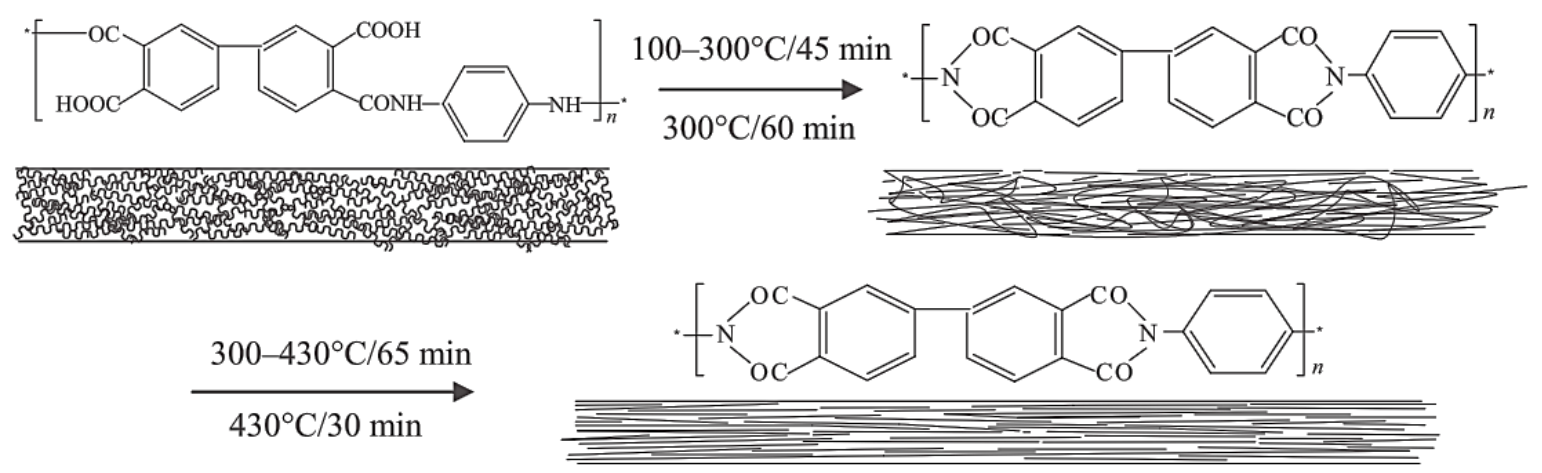

Mechanical tests indicated that the average tensile strength and modulus of these nanofiber mats with fiber diameters of around $300 \mathrm{~nm}$ were $660 \mathrm{MPa}$ and $15 \mathrm{GPa}$, respectively. Further studies showed that the ultimate tensile strength and Young's modulus could reach values of $1.7 \mathrm{GPa}$ and $76 \mathrm{GPa}$, which are comparable to conventional BPDA-PDA fibers [103] and are in the region of commercial high performance fibers.

\subsection{Other Routes to High Performance Nanofibers}

\subsubsection{CNT Reinforced Polymer Nanofibers}

Carbon nanotubes, due to their excellent mechanical properties, have been regarded as ideal reinforcement candidates for nanocomposites [104-106]. Basically, the Young's modulus and tensile strength of single-wall carbon nanotubes (SWCNTs) are reported to reach about $1 \mathrm{TPa}$ and tens of GPa's [107,108], respectively, outperforming most other materials.

Generally, CNTs are however prone to aggregation and bundling because of their small diameter and strong Van der Waals interactions, lowering their reinforcing capability. Therefore, three main challenges are encountered when using carbon nanotubes as nano-reinforcements in polymer fibers. Firstly, the creation of a homogenous spinnable dispersion of CNTs. Secondly, a good interfacial adhesion and stress transfer, and finally orientation of the CNTs in the polymer fiber [109-111]. Electrospinning is a promising technique to produce CNT reinforced nanofibers since it has the potential to debundle and align CNTs along the fiber axis and thus effectively reinforce the nanofiber [112-114], 
while interfacial interactions between CNTs and host polymer can be enhanced by functionalization of the CNTs [115].

Sen et al [115] reported on ester-functionalized SWCNTs reinforced electrospun polyurethane (PU) nanofibers. Mechanical tests showed that the tensile strength of these ester-functionalized SWCNT reinforced nanofiber membranes were improved by 104\%, while elastic moduli were increased by $250 \%$ compared to pure PU membranes, with improvements of these properties being mainly attributed to alignments and improved interfacial interactions between SWCNTs and polymer matrix.

Baji et al. investigated the mechanical properties of multi-wall carbon nanotube (MWCNT) reinforced nylon 6,6 nanofibers [116]. In their study, carboxylic acid functional groups modified MWCNTs were mixed together with nylon 6,6 in different concentrations. These mixtures were electrospun into aligned nanofibers using parallel plate electrodes. Mechanical tests showed that the tensile strength and Young's modulus of the composite nanofibers increased with CNT loading, reaching peak values (from about $0.32 \mathrm{GPa}$ and $1.2 \mathrm{GPa}$ to $0.65 \mathrm{GPa}$ and $3.5 \mathrm{GPa}$, respectively) for CNT concentrations of $7.5 \mathrm{wt} \%$. This significant improvement in mechanical properties was claimed to be due to among others the good dispersion and alignment of the MWCNTs along the nanofiber axis as confirmed by TEM. Other studies involving CNT reinforced nanofibers were reported by Hou et al. [117], Jose et al. [118], Lu et al. [119], and Wang et al. [120].

A careful analysis of the reinforcing efficiency of CNTs in the composite fibers should be emphasized here since high reinforcing efficiency of CNTs in composites is generally a good indication of effective dispersion, interfacial interaction and alignment. Wang et al. [121] reported on solid-state drawn nanocomposite PVA/SWCNTs tapes and found a remarkable reinforcing efficiency for systems incorporating up to $1 \mathrm{wt} \%$ of SWCNTs. Further studies on nanotube reinforced electrospun PVA nanofibers (Figure 19) revealed similar high reinforcing efficiencies, with a back-calculated SWCNT Young's modulus of around 0.85 TPa [120], i.e., close to its theoretical 1 TPa value.

Despite various developments in CNT reinforced nanofibers, in many cases, eliminating agglomeration and achieving homogenous spinnable solutions and good alignment remain a challenge especially at higher CNT concentrations. Moreover, even for systems that report significant property improvements these properties are often still not very impressive when compared to commercial high performance fibers.

Figure 19. TEM micrograph of an individual MWCNT reinforced electrospun PVA nanofiber, showing an aligned MWCNT in a polymer nanofiber (scale bar $100 \mathrm{~nm}$ ) [120].

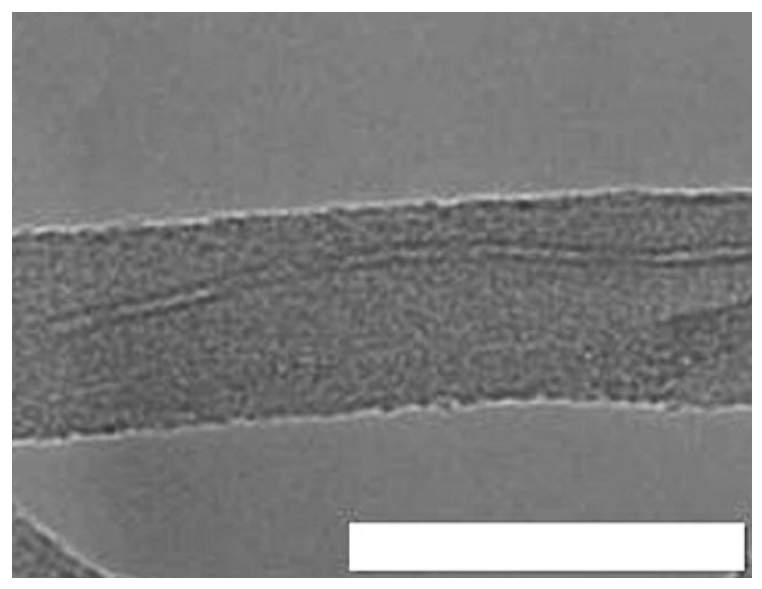




\subsubsection{Electrospun Polymer-derived Carbon Nanofibers}

Another interesting approach towards high strength and high modulus nanofibers is the development of carbon nanofibers. Polymer nanofiber precursors prepared via electrospinning followed by carbonization have been investigated [122]. Several polymers have been investigated as precursors for carbon fibers. Principally, polyacrylonitrile is used [123-127], while pitches [128,129], poly(vinyl alcohol) (PVA) [130], polyimide (PI) [131], poly(vinylidenfluoride) (PVDF) [132], and polybenzimidazol (PBI) [133] have also been utilized.

Zussman et al. created single electrospun PAN-derived carbon nanofibers with different fiber diameters possessing Young's moduli of $63 \pm 7$ GP and tensile strengths between $0.32 \mathrm{GPa}$ and $0.9 \mathrm{GPa}$. Inferior mechanical properties of these electrospun PAN-based carbon nanofibers compared to commercial carbon fibers resulted from the relatively poor molecular orientation and disarrangements in the core-shell structure of the carbon nanofibers [124]. PAN-based carbon nanofibers were also prepared by Zhou et al. [127]. Young's moduli of 40 to $60 \mathrm{GPa}$ and tensile strengths of 0.3 to $0.6 \mathrm{GPa}$ for carbon nanofiber bundles were achieved and mechanical properties were found to increase with carbonization temperature. In addition, the authors proposed possible ways to further enhance the mechanical properties of these PAN-based carbon nanofibers, i.e., by post-drawing of precursor fibers; the stabilization and carbonization of nanofibers under tension; and the use of PAN copolymer as a precursor. Optimized process conditions for strong carbon nanofibers based on PAN were reported by Chasiotis and co-workers [134]. Both the PAN precursor nanofibers and carbon nanofibers were smooth and uniform (Figure 20). Young's moduli of $191 \pm 58 \mathrm{GPa}$ upon carbonization at $1700{ }^{\circ} \mathrm{C}$ and tensile strengths of $3.52 \pm 0.64 \mathrm{GPa}$ upon carbonization at $1400{ }^{\circ} \mathrm{C}$ were reported, and were attributed to an increase in crystallites in the carbon nanofibers, making these fibers approach the mechanical performance of standard high-strength carbon fibers.

Figure 20. (a) SEM micrograph and (b) TEM micrograph showing homogenous morphology of carbon nanofibers [134]. Reproduced with permission from Arshad et al., 2011. Copyright by Elsevier Publisher.

(a)

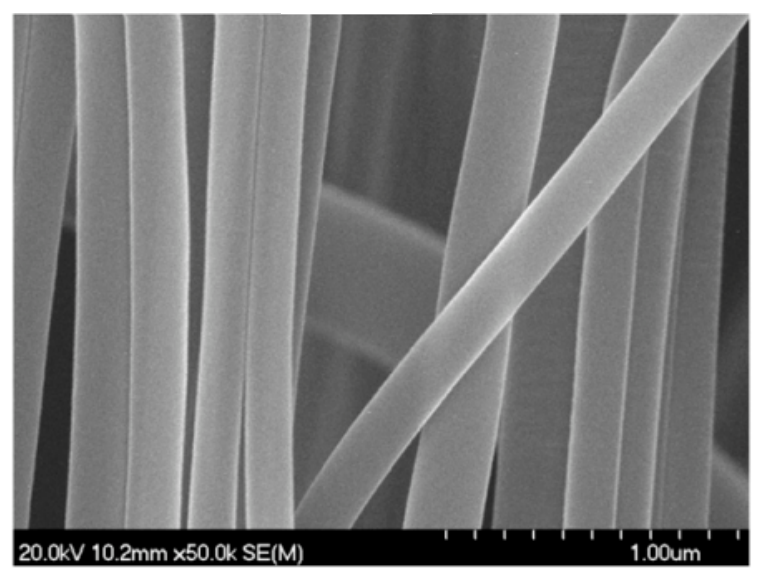

(b)

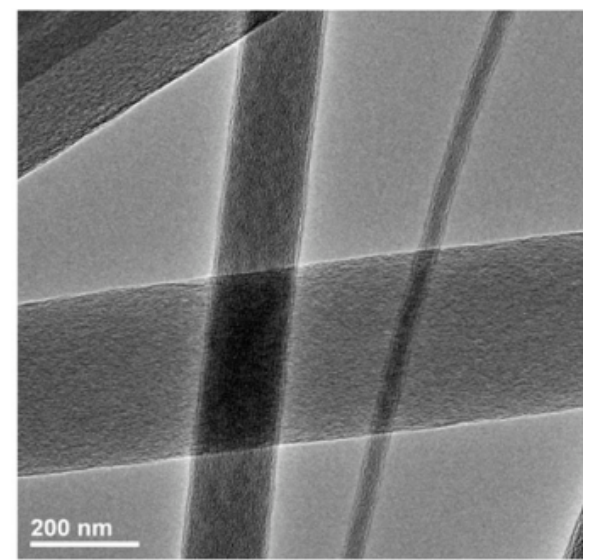


Figure 21. Mechanical properties of traditional high performance fibers and electrospun nanofibers with respect to Young's modulus and tensile strength. Commercial high-performance fibers show typical tensile strengths of 3-4 GPa and moduli of around 100-300 GPa, while most electrospun fibers typically possess tensile strengths $<0.3 \mathrm{GPa}$ and Young's moduli < 3 GPa [65-71,73]. Some high performance electrospun nanofibers have been reported based on polyimide [102], polyacrylonitrile [90] and carbon nanofibers from electrospun PAN precursors [134].

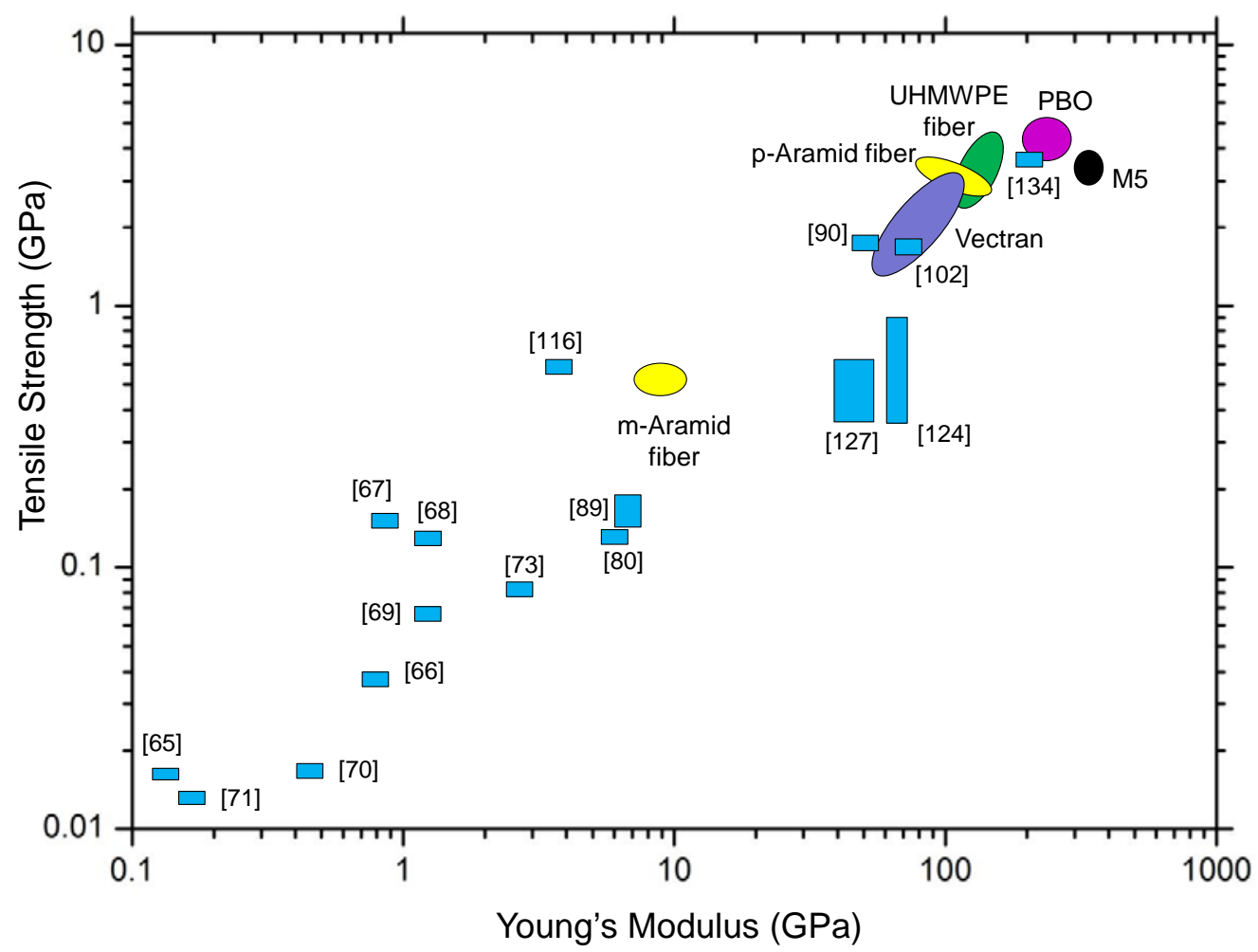

\section{Conclusions}

Electrospinning has proven to be an efficient method to produce thin fibers with diameters down to the nano-scale. However, the mechanical properties of these nanofibers are often well below those of fibers made by conventional processes such melt- or solution spinning (see Figure 21). The main reason for this being the competition between flow-induced chain orientation and chain relaxation before fiber solidification, leading to low degrees of molecular orientation in as-spun fibers. In conventional polymer fiber processing, chain alignment is induced by drawing the as-spun fiber in the solid-state below the melting temperature into a highly oriented structure as here relaxation times are infinite. In order to achieve similar high levels of chain orientation and chain extension in nanofibers based on flexible chain polymers it is vital to apply a post-stretching step.

Although some evidence exists of confinement induced molecular orientation in the case of ultra-fine nanofibers, the orientation and particularly chain extension achieved is often rather limited, leading to only moderate improvements in Young's modulus (typically 2-4 times bulk polymer), well below those attainable in commercial melt- or solution spun fibers (typically 10-100 times bulk polymer). 
As the introduction of a post-drawing step in commercial electrospinning processes may prove technologically challenging, the use of rigid-rod polymers as an alternative to flexible chain polymers may be more promising as here chains have already build in chain extension and can be readily oriented during spinning. Other alternative routes worth pursuing are the use of nano-reinforcements such as carbon nanotubes or transforming polymer precursor fibers into carbon nanofibers, with especially the latter showing some great promise for future work.

\section{Acknowledgments}

The first author gratefully acknowledges the support from the China Scholarship Council (CSC).

\section{Author Contributions}

All authors contributed equally to this work.

\section{Conflicts of Interest}

The authors declare no conflict of interest.

\section{References}

1. Doshi, J.; Reneker, D.H. Electrospinning process and applications of electrospun fibers. J. Electrost. 1995, 35, 151-160.

2. Reneker, D.H.; Chun, I. Nanometre diameter fibres of polymer, produced by electrospinning. Nanotechnology 1996, 7, 216.

3. Fong, H.; Chun, I.; Reneker, D. Beaded nanofibers formed during electrospinning. Polymer 1999, 40, 4585-4592.

4. Kim, J.S.; Reneker, D.H. Mechanical properties of composites using ultrafine electrospun fibers. Polym. Compos.1999, 20, 124-131.

5. Jaeger, R.; Bergshoef, M.M.; Batlle, C.M.I.; Schönherr, H.; Julius Vancso, G. In Electrospinning of Ultra-thin Polymer Fibers, Macromolecular Symposia, 1998; Wiley Online Library: Hoboken, NJ, USA, 1998; pp. 141-150.

6. Bognitzki, M.; Czado, W.; Frese, T.; Schaper, A.; Hellwig, M.; Steinhart, M.; Greiner, A.; Wendorff, J.H. Nanostructured fibers via electrospinning. Adv. Mater. 2001, 13, 70-72.

7. Fang, X.; Reneker, D. DNA fibers by electrospinning. J. Macromol. Sci. Part B Phys. 1997, 36, 169-173.

8. Fong, H.; Reneker, D.H. Elastomeric nanofibers of styrene-butadiene-styrene triblock copolymer. J. Macromol. Sci. Part B Phys. 1999, 37, 3488-3493.

9. Ramakrishna, S. An Introduction to Electrospinning and Nanofibers; World Scientific Publishing Co. Pte. Ltd: Singapore: 2005; pp. 90-154.

10. Xu, C.; Inai, R.; Kotaki, M.; Ramakrishna, S. Aligned biodegradable nanofibrous structure: A potential scaffold for blood vessel engineering. Biomaterials 2004, 25, 877-886.

11. Huang, Z.-M.; Zhang, Y.-Z.; Kotaki, M.; Ramakrishna, S. A review on polymer nanofibers by electrospinning and their applications in nanocomposites. Compos. Sci. Technol. 2003, 63, 2223-2253. 
12. Greiner, A.; Wendorff, J. Functional self-assembled nanofibers by electrospinning. In Self-Assembled Nanomaterials I; Springer Berlin Heidelberg: Berlin, Germany, 2008; pp. 107-171.

13. Wang, J.; Kim, S.C.; Pui, D.Y. Investigation of the figure of merit for filters with a single nanofiber layer on a substrate. J. Aerosol. Sci. 2008, 39, 323-334.

14. Nair, L.S.; Bhattacharyya, S.; Bender, J.D.; Greish, Y.E.; Brown, P.W.; Allcock, H.R.; Laurencin, C.T. Fabrication and optimization of methylphenoxy substituted polyphosphazene nanofibers for biomedical applications. Biomacromolecules 2004, 5, 2212-2220.

15. Lee, K.; Kim, H.; Khil, M.; Ra, Y.; Lee, D. Characterization of nano-structured poly (E-caprolactone) nonwoven mats via electrospinning. Polymer 2003, 44, 1287-1294.

16. Lee, K.H.; Kim, H.Y.; Ryu, Y.J.; Kim, K.W.; Choi, S.W. Mechanical behavior of electrospun fiber mats of poly (vinyl chloride)/polyurethane polyblends. J. Polym. Sci. Part B Polym. Phys. 2003, 41, 1256-1262.

17. Huang, Z.-M.; Zhang, Y.; Ramakrishna, S.; Lim, C. Electrospinning and mechanical characterization of gelatin nanofibers. Polymer 2004, 45, 5361-5368.

18. Hansen, L.M.; Smith, D.J.; Reneker, D.H.; Kataphinan, W. Water absorption and mechanical properties of electrospun structured hydrogels. J. Appl. Polym. Sci. 2005, 95, 427-434.

19. Matthews, J.A.; Wnek, G.E.; Simpson, D.G.; Bowlin, G.L. Electrospinning of collagen nanofibers. Biomacromolecules 2002, 3, 232-238.

20. Staudinger, H. Über polymerisation. Ber. Deutsch. Chem. Ges. (A and B Series) 1920, 53, 1073-1085. (in German).

21. Heeger, A.J. Nobel Lecture: Semiconducting and metallic polymers: The fourth generation of polymeric materials. Rev. Mod. Phys. 2001, 73, 681-700.

22. Dasgupta, S.; Hammond, W.B.; Goddard, W.A. Crystal structures and properties of nylon polymers from theory. J. Am.Chem. Soc. 1996, 118, 12291-12301.

23. Cook, J.G. Handbook of Textile Fibres: Man-Made Fibres; Woodhead Publishing Limited: Cambridge, UK, 1984; pp. 192-391.

24. Staudinger, H. Die Hochmolekularen im festen Zustand. In Die Hochmolekularen Organischen Verbindungen-Kautschuk und Cellulose; Springer: Berlin/Heidelberg, Germany, 1932; pp. 105-123. (in German).

25. Meyer, K.H.; Lotmar, W.; Pankow, G. Sur le chlorure de poly-phosphornitrile, caoutchouc inorganique. Helvetica. Chimica. Acta. 1936, 19, 930-948. (in French).

26. Treloar, L.G. Calculations of elastic moduli of polymer crystals: I. Polyethylene and nylon 66. Polymer 1960, 1, 95-103.

27. Peijs, A.; Jacobs, M.; Lemstra, P. High-performance polyethylene fibers. In Comprehensive Composite Materials. Vol. 1. Fiber Reinforcements and General Theory of Composites; Chou, T.W., Kelly, A., Zweben, C., Eds.; Elsevier: Amsterdam, the Netherlands, 2000; pp. 263-301.

28. Hageman, J.; Meier, R.J.; Heinemann, M.; De Groot, R. Young modulus of crystalline polyethylene from ab initio molecular dynamics. Macromolecules 1997, 30, 5953-5957.

29. Crist, B. The ultimate strength and stiffness of polymers. Ann. Rev. Mater. Sci. 1995, 25, 295-323.

30. Manley, T.; Martin, C. Elastic modulus of linear polymer crystals. Polymer 1973, 14, 491-496. 
31. Nakamae, K.; Nishino, T. Crystal moduli of high polymers and their temperature dependence. In Integration of Fundamental Polymer Science and Technology-5; Lemstra, P., Kleintjens, L., Eds.; Springer: Houten, the Netherlands, 1991; pp. 121-130.

32. Lemstra, P.; Kirschbaum, R.; Ohta, T.; Yasuda, H. High-strength/high-modulus structures based on flexible macromolecules: Gel-spinning and related processes. In Developments in Oriented Polymers-2; Springer: Houten, the Netherlands, 1987; pp. 39-77.

33. Lemstra, P.; Van Aerle, N.; Bastiaansen, C. Chain-extended polyethylene. Polym. J. 1987, 19, 85-98.

34. Lemstra, P.; Bastiaansen, C.; Meijer, H. Chain-extended flexible polymers. Die Angew. Makromol. Chem. 1986, 145, 343-358.

35. Bastiaansen, C.W.; Simmelink, J.A.P.M. Solution of ultra-high molecular weight polyethylene. US Patent 5,428,079, filed 30 July 1991, and issued 27 June 1995.

36. Capaccio, G.; Ward, I. Ultra-high-modulus linear polyethylene through controlled molecular weight and drawing. Polym. Eng. Sci.1975, 15, 219-224.

37. Cansfield, D.; Capaccio, G.; Ward, I. The preparation of ultra-high modulus polypropylene films and fibres. Polym. Eng. Sci. 1976, 16, 721-724.

38. Zwijnenburg, A.; Pennings, A. Longitudinal growth of polymer crystals from flowing solutions III. Polyethylene crystals in Couette flow. Colloid Polym. Sci. 1976, 254, 868-881.

39. Zwijnenburg, A.; Pennings, A. Longitudinal growth of polymer crystals from flowing solutions. IV. The mechanical properties of fibrillar polyethylene crystals. J. Polym. Sci. Polym. Lett. Ed. 1976, 14, 339-346.

40. Ajji, A.; Coates, P.; Dumoulin, M.; Ward, I. Solid Phase Processing of Polymers; Carl Hanser Verlag: Munich, Germany, 2000; pp. 85-210.

41. Smith, P.; Lemstra, P.J. Ultrahigh-strength polyethylene filaments by solution spinning/drawing, 2. Influence of solvent on the drawability. Die Makromol. Chem. 1979, 180, 2983-2986.

42. Smith, P.; Lemstra, P.J.; Pijpers, J.P. Tensile strength of highly oriented polyethylene. II. Effect of molecular weight distribution. J. Polym. Sci.: Polym. Phys. Ed. 1982, 20, 2229-2241.

43. Smith, P.; Lemstra, P.; Pijpers, J.; Kiel, A. Ultra-drawing of high molecular weight polyethylene cast from solution. Colloid Polym. Sci. 1981, 259, 1070-1080.

44. Smith, P.; Lemstra, P.J. Filaments of high tensile strength and modulus. US Patent 4,430,383, filed 30 September 1982, and issued 7 February 1984.

45. Kwolek, S.L. Optically anisotropic aromatic polyamide dopes. US Patent 3,671,542, filed 23 May 1969, and issued 20 June 1972.

46. Kwolek, S.; Morgan, P.; Schaefgen, J.; Gulrich, L. Synthesis, anisotropic solutions, and fibers of poly (1, 4-benzamide). Macromolecules 1977, 10, 1390-1396.

47. Yang, H. Kevlar Aramid Fiber; John Wiley \& Sons: Chichester, NH, USA; 1993; pp. 1-22.

48. Bair, T.; Morgan, P.; Killian, F. Poly (1, 4-phenyleneterephthalamides). polymerization and novel liquid-crystalline solutions. Macromolecules 1977, 10, 1396-1400.

49. Blades, H. High modulus, high tenacity poly (p-phenylene terephthalamide) fiber. US Patent 3,869,430, filed 30 June 1972, and issued 4 March 1975.

50. Dobb, M.; Johnson, D.; Saville, B. Supramolecular structure of a high-modulus polyaromatic fiber (Kevlar 49). J. Polym. Sci.: Polym. Phys. Ed. 1977, 15, 2201-2211. 
51. Hearle, J.W. High-Performance Fibres; Woodhead Publishing: Cambridge, UK, 2001; Volume 15, pp. 93-155.

52. Kumar, S.; Dang, T.D.; Arnold, F.E.; Bhattacharyya, A.R.; Min, B.G.; Zhang, X.; Vaia, R.A.; Park, C.; Adams, W.W.; Hauge, R.H. Synthesis, Structure, and Properties of PBO/SWNT Composites. Macromolecules 2002, 35, 9039-9043.

53. Kitagawa, T.; Murase, H.; Yabuki, K. Morphological study on poly(p-phenylenebenzobisoxazole) (PBO) fiber. J. Polym. Sci. Part B Polym. Phys. 1998, 36, 39-48.

54. Choe, E.W.; Kim, S.N. Synthesis, spinning, and fiber mechanical properties of poly (p-phenylenebenzobisoxazole). Macromolecules 1981, 14, 920-924.

55. Sikkema, D.J. Design, synthesis and properties of a novel rigid rod polymer, PIPD or M5: High modulus and tenacity fibres with substantial compressive strength. Polymer 1998, 39, 5981-5986.

56. Sirichaisit, J.; Young, R. Tensile and compressive deformation of polypyridobisimidazole (PIPD)-based M5 rigid-rod polymer fibres. Polymer 1999, 40, 3421-3431.

57. Greiner, A.; Wendorff, J.H. Electrospinning: a fascinating method for the preparation of ultrathin fibers. Angew. Chem. Int. Ed. 2007, 46, 5670-5703.

58. Li, D.; Xia, Y. Electrospinning of nanofibers: reinventing the wheel? Adv. Mater. 2004, 16, 1151-1170.

59. Petrik, S.; Maly, M. In Production Nozzle-less Electrospinning Nanofiber Technology, MRS Proceedings, 2009; Materials Research Society: Warrendale, PA, USA, 2009.

60. Erisken, C.; Kalyon, D.M.; Wang, H. A hybrid twin screw extrusion/electrospinning method to process nanoparticle-incorporated electrospun nanofibres. Nanotechnology 2008, 19, 165302.

61. Senturk-Ozer, S.; Ward, D.; Gevgilili, H.; Kalyon, D.M. Dynamics of electrospinning of poly (caprolactone) via a multi-nozzle spinneret connected to a twin screw extruder and properties of electrospun fibers. Polym. Eng. Sci. 2013, 53, 1463-1474.

62. Badrossamay, M.R.; Mcllwee, H.A.; Goss, J.A.; Parker, K.K. Nanofiber assembly by rotary jet-spinning. Nano Lett. 2010, 10, 2257-2261.

63. Rein, D.M.; Shavit-Hadar, L.; Khalfin, R.; Cohen, Y.; Shuster, K.; Zussman, E. Electrospinning of ultrahigh-molecular-weight polyethylene nanofibers. J. Polym. Sci. Part B Polym. Phys. 2007, 45, 766-773.

64. Peijs, T.; Rijsdijk, H.; De Kok, J.; Lemstra, P. The role of interface and fibre anisotropy in controlling the performance of polyethylene-fibre-reinforced composites. Compos. Sci. Technol. 1994, 52, 449-466.

65. Carrizales, C.; Pelfrey, S.; Rincon, R.; Eubanks, T.M.; Kuang, A.; McClure, M.J.; Bowlin, G.L.; Macossay, J. Thermal and mechanical properties of electrospun PMMA, PVC, Nylon 6, and Nylon 6, 6. Polym. Adv. Technol. 2008, 19, 124-130.

66. Bazbouz, M.B.; Stylios, G.K. The tensile properties of electrospun nylon 6 single nanofibers. J. Polym. Sci. Part B Polym. Phys. 2010, 48, 1719-1731.

67. Zussman, E.; Burman, M.; Yarin, A.; Khalfin, R.; Cohen, Y. Tensile deformation of electrospun nylon-6, 6 nanofibers. J. Polym. Sci. Part B Polym. Phys. 2006, 44, 1482-1489.

68. Sanatgar, R.H.; Borhani, S.; Ravandi, S.A.H.; Gharehaghaji, A.A. The influence of solvent type and polymer concentration on the physical properties of solid state polymerized PA66 nanofiber yarn. J. Appl. Polym. Sci. 2012, 126, 1112-1120. 
69. Hang, F.; Lu, D.; Bailey, R.J.; Jimenez-Palomar, I.; Stachewicz, U.; Cortes-Ballesteros, B.; Davies, M.; Zech, M.; Bödefeld, C.; Barber, A.H. In situ tensile testing of nanofibers by combining atomic force microscopy and scanning electron microscopy. Nanotechnology 2011, 22, 365708.

70. Stachewicz, U.; Peker, I.; Tu, W.; Barber, A.H. Stress delocalization in crack tolerant electrospun nanofiber networks. ACS Appl. Mater. Interfaces 2011, 3, 1991-1996.

71. Veleirinho, B.; Rei, M.F.; Lopes-DA-Silva, J. Solvent and concentration effects on the properties of electrospun poly (ethylene terephthalate) nanofiber mats. J. Polym. Sci. Part B Polym. Phys. 2008, 46, 460-471.

72. Zong, X.; Ran, S.; Fang, D.; Hsiao, B.S.; Chu, B. Control of structure, morphology and property in electrospun poly (glycolide-co-lactide) non-woven membranes via post-draw treatments. Polymer 2003, 44, 4959-4967.

73. Wu, S.Z.; Yang, X.P.; Zhang, F.; Hou, X.X. Stretching-induced orientation for improving the mechanical properties of electrospun polyacrylonitrile nanofiber sheet. Adv. Mater. Res. 2008, 47, 1169-1172.

74. Kongkhlang, T.; Tashiro, K.; Kotaki, M.; Chirachanchai, S. Electrospinning as a new technique to control the crystal morphology and molecular orientation of polyoxymethylene nanofibers. J. Am. Chem. Soc. 2008, 130, 15460-15466.

75. Huang, C.; Chen, S.; Reneker, D.H.; Lai, C.; Hou, H. High-Strength Mats from Electrospun Poly (p-Phenylene Biphenyltetracarboximide) Nanofibers. Adv. Mater. 2006, 18, 668-671.

76. Mohan, S.D.; Mitchell, G.R.; Davis, F.J. Chain extension in electrospun polystyrene fibres: A SANS study. Soft Matter 2011, 7, 4397-4404.

77. Tan, E.; Lim, C. Physical properties of a single polymeric nanofiber. Appl. Phys. Lett. 2004, 84, 1603-1605.

78. Lim, C.; Tan, E.; Ng, S. Effects of crystalline morphology on the tensile properties of electrospun polymer nanofibers. Appl. Phys. Lett. 2008, 92, 141908-141908-141903.

79. Bashur, C.A.; Dahlgren, L.A.; Goldstein, A.S. Effect of fiber diameter and orientation on fibroblast morphology and proliferation on electrospun poly (D,L-lactic-co-glycolic acid) meshes. Biomaterials 2006, 27, 5681-5688.

80. Pai, C.-L.; Boyce, M.C.; Rutledge, G.C. Mechanical properties of individual electrospun PA 6(3)T fibers and their variation with fiber diameter. Polymer 2011, 52, 2295-2301.

81. Chew, S.Y.; Hufnagel, T.C.; Lim, C.T.; Leong, K.W. Mechanical properties of single electrospun drug-encapsulated nanofibres. Nanotechnology 2006, 17, 3880.

82. Shin, M.K.; Kim, S.I.; Kim, S.J.; Kim, S.-K.; Lee, H.; Spinks, G.M. Size-dependent elastic modulus of single electroactive polymer nanofibers. Appl. Phys. Lett. 2006, 89, 231923-231929.

83. Fennessey, S.F.; Farris, R.J. Fabrication of aligned and molecularly oriented electrospun polyacrylonitrile nanofibers and the mechanical behavior of their twisted yarns. Polymer 2004, 45, 4217-4225.

84. Kim, J.S.; Reneker, D.H. Polybenzimidazole nanofiber produced by electrospinning. Polym. Eng. Sci. 1999, 39, 849-854.

85. Stachewicz, U.; Bailey, R.J.; Wang, W.; Barber, A.H. Size dependent mechanical properties of electrospun polymer fibers from a composite structure. Polymer 2012, 53, 5132-5137. 
86. Schellekens, R.; Bastiaansen, C. The drawing behavior of polyvinylalcohol fibers. J. Appl. Polym. Sci. 1991, 43, 2311-2315.

87. Arinstein, A.; Zussman, E. Electrospun polymer nanofibers: Mechanical and thermodynamic perspectives. J. Polym. Sci. Part B Polym. Phys.2011, 49, 691-707.

88. Arinstein, A.; Burman, M.; Gendelman, O.; Zussman, E. Effect of supramolecular structure on polymer nanofibre elasticity. Nat. Nanotechnol. 2007, 2, 59-62.

89. Naraghi, M.; Arshad, S.; Chasiotis, I. Molecular orientation and mechanical property size effects in electrospun polyacrylonitrile nanofibers. Polymer 2011, 52, 1612-1618.

90. Papkov, D.; Zou, Y.; Andalib, M.N.; Goponenko, A.; Cheng, S.Z.; Dzenis, Y.A. Simultaneously Strong and Tough Ultrafine Continuous Nanofibers. ACS Nano 2013, 7, 3324-3331.

91. Allen, R.; Ward, I.; Bashir, Z. An investigation into the possibility of measuring an 'X-ray modulus' and new evidence for hexagonal packing in polyacrylonitrile. Polymer 1994, 35, 2063-2071.

92. Sawai, D.; Fujii, Y.; Kanamoto, T. Development of oriented morphology and tensile properties upon superdawing of solution-spun fibers of ultra-high molecular weight poly (acrylonitrile). Polymer 2006, 47, 4445-4453.

93. Brandrup, J.; Immergut, E.H.; Grulke, E.A.; Abe, A.; Bloch, D.R. Polymer Handbook, 4th ed.; John Wiley \& Sons: New York, NY, USA, 1999; Vol. 5, pp. 61.

94. Lewin, M. Handbook of Fiber Chemistry, 3rd Ed.; Taylor \& Francis Group: Boca Raton, FL, USA, 2006; pp. 812-958.

95. Bisschops, J. Gelation of concentrated polyacrylonitrile solutions. II. J. Polym. Sci. 1955, 17, 89-98.

96. Cleland, R.L.; Stockmayer, W.H. An intrinsic viscosity-molecular weight relation for polyacrylonitrile. J. Polym. Sci. 1955, 17, 473-477.

97. Reneker, D.H.; Yarin, A.L.; Fong, H.; Koombhongse, S. Bending instability of electrically charged liquid jets of polymer solutions in electrospinning. J. Appl. Phys. 2000, 87, 4531.

98. Theron, S.; Zussman, E.; Yarin, A. Experimental investigation of the governing parameters in the electrospinning of polymer solutions. Polymer 2004, 45, 2017-2030.

99. Richard-Lacroix, M.; Pellerin, C. Molecular Orientation in Electrospun Fibers: From Mats to Single Fibers. Macromolecules 2013, 46, 9473-9493.

100. Srinivasan, G.; Reneker, D.H. Structure and morphology of small diameter electrospun aramid fibers. Polym. Int. 1995, 36, 195-201.

101. Huang, C.; Wang, S.; Zhang, H.; Li, T.; Chen, S.; Lai, C.; Hou, H. High strength electrospun polymer nanofibers made from BPDA-PDA polyimide. Eur. Polym. J. 2006, 42, 1099-1104.

102. Chen, F.; Peng, X.; Li, T.; Chen, S.; Wu, X.-F.; Reneker, D.H.; Hou, H. Mechanical characterization of single high-strength electrospun polyimide nanofibres. J. Phys. D Appl. Phys. 2008, 41, 025308.

103. Kaneda, T.; Katsura, T.; Nakagawa, K.; Makino, H.; Horio, M. High-strength-high-modulus polyimide fibers I. One-step synthesis of spinnable polyimides. J. Appl. Polym. Sci. 1986, 32, 3133-3149.

104. Baughman, R.H.; Zakhidov, A.A.; de Heer, W.A. Carbon nanotubes-The route toward applications. Science 2002, 297, 787-792. 
105. Thostenson, E.T.; Ren, Z.; Chou, T.-W. Advances in the science and technology of carbon nanotubes and their composites: a review. Compos. Sci. Technol. 2001, 61, 1899-1912.

106. Hussain, F.; Hojjati, M.; Okamoto, M.; Gorga, R.E. Review article: Polymer-matrix nanocomposites, processing, manufacturing, and application: An overview. J. Compos. Mater. 2006, 40, 1511-1575.

107. Yu, M.-F.; Files, B.S.; Arepalli, S.; Ruoff, R.S. Tensile loading of ropes of single wall carbon nanotubes and their mechanical properties. Phys. Rev. Lett. 2000, 84, 5552.

108. Shenderova, O.; Brenner, D.; Ruoff, R.S. Would diamond nanorods be stronger than fullerene nanotubes? Nano Lett. 2003, 3, 805-809.

109. Biercuk, M.; Llaguno, M.C.; Radosavljevic, M.; Hyun, J.; Johnson, A.T.; Fischer, J.E. Carbon nanotube composites for thermal management. Appl. Phys. Lett. 2002, 80, 2767-2769.

110. Xie, X.-L.; Mai, Y.-W.; Zhou, X.-P. Dispersion and alignment of carbon nanotubes in polymer matrix: a review. Mater. Sci. Eng. R Rep. 2005, 49, 89-112.

111. Grossiord, N.; Loos, J.; Regev, O.; Koning, C.E. Toolbox for dispersing carbon nanotubes into polymers to get conductive nanocomposites. Chem. Mater. 2006, 18, 1089-1099.

112. Salalha, W.; Dror, Y.; Khalfin, R.L.; Cohen, Y.; Yarin, A.L.; Zussman, E. Single-walled carbon nanotubes embedded in oriented polymeric nanofibers by electrospinning. Langmuir 2004, 20, 9852-9855.

113. Wan, Y.Q.; He, J.H.; Yu, J.Y. Carbon nanotube-reinforced polyacrylonitrile nanofibers by vibration-electrospinning. Polym. Int. 2007, 56, 1367-1370.

114. Kannan, P.; Eichhorn, S.J.; Young, R.J. Deformation of isolated single-wall carbon nanotubes in electrospun polymer nanofibres. Nanotechnology 2007, 18, 235707.

115. Sen, R.; Zhao, B.; Perea, D.; Itkis, M.E.; Hu, H.; Love, J.; Bekyarova, E.; Haddon, R.C. Preparation of single-walled carbon nanotube reinforced polystyrene and polyurethane nanofibers and membranes by electrospinning. Nano Lett. 2004, 4, 459-464.

116. Baji, A.; Mai, Y.-W.; Wong, S.-C.; Abtahi, M.; Du, X. Mechanical behavior of self-assembled carbon nanotube reinforced nylon 6, 6 fibers. Compos. Sci. Technol. 2010, 70, 1401-1409.

117. Hou, H.; Ge, J.J.; Zeng, J.; Li, Q.; Reneker, D.H.; Greiner, A.; Cheng, S.Z. Electrospun polyacrylonitrile nanofibers containing a high concentration of well-aligned multiwall carbon nanotubes. Chem. Mater. 2005, 17, 967-973.

118. Jose, M.V.; Steinert, B.W.; Thomas, V.; Dean, D.R.; Abdalla, M.A.; Price, G.; Janowski, G.M. Morphology and mechanical properties of Nylon 6/MWNT nanofibers. Polymer 2007, 48, 1096-1104.

119. Lu, P.; Hsieh, Y.-L. Multiwalled carbon nanotube (MWCNT) reinforced cellulose fibers by electrospinning. ACS Appl. Mater. Interfaces 2010, 2, 2413-2420.

120. Wang, W.; Ciselli, P.; Kuznetsov, E.; Peijs, T.; Barber, A. Effective reinforcement in carbon nanotube-polymer composites. Philos. Trans. R. Soc. A Math. Phys. Eng. Sci. 2008, 366, 1613-1626.

121. Wang, Z.; Ciselli, P.; Peijs, T. The extraordinary reinforcing efficiency of single-walled carbon nanotubes in oriented poly (vinyl alcohol) tapes. Nanotechnology 2007, 18, 455709.

122. Inagaki, M.; Yang, Y.; Kang, F. Carbon nanofibers prepared via electrospinning. Adv. Mater. 2012, 24, 2547-2566. 
123. Kim, C.; Yang, K.S.; Kojima, M.; Yoshida, K.; Kim, Y.J.; Kim, Y.A.; Endo, M. Fabrication of Electrospinning-Derived Carbon Nanofiber Webs for the Anode Material of Lithium-Ion Secondary Batteries. Adv. Funct. Mater. 2006, 16, 2393-2397.

124. Zussman, E.; Chen, X.; Ding, W.; Calabri, L.; Dikin, D.; Quintana, J.; Ruoff, R. Mechanical and structural characterization of electrospun PAN-derived carbon nanofibers. Carbon 2005, 43, 2175-2185.

125. Zussman, E.; Yarin, A.L.; Bazilevsky, A.V.; Avrahami, R.; Feldman, M. Electrospun Polyaniline/Poly (methyl methacrylate)-Derived Turbostratic Carbon Micro-/Nanotubes. Adv. Mater. 2006, 18, 348-353.

126. Kim, C.; Jeong, Y.I.; Ngoc, B.T.N.; Yang, K.S.; Kojima, M.; Kim, Y.A.; Endo, M.; Lee, J.W. Synthesis and characterization of porous carbon nanofibers with hollow cores through the thermal treatment of electrospun copolymeric nanofiber webs. Small 2007, 3, 91-95.

127. Zhou, Z.; Lai, C.; Zhang, L.; Qian, Y.; Hou, H.; Reneker, D.H.; Fong, H. Development of carbon nanofibers from aligned electrospun polyacrylonitrile nanofiber bundles and characterization of their microstructural, electrical, and mechanical properties. Polymer 2009, 50, 2999-3006.

128. Park, S.H.; Kim, C.; Choi, Y.O.; Yang, K.S. Preparations of pitch-based CF/ACF webs by electrospinning. Carbon 2003, 41, 2655-2657.

129. Park, S.H.; Kim, C.; Yang, K.S. Preparation of carbonized fiber web from electrospinning of isotropic pitch. Synth. Met. 2004, 143, 175-179.

130. Zou, L.; Gan, L.; Lv, R.; Wang, M.; Huang, Z.-h.; Kang, F.; Shen, W. A film of porous carbon nanofibers that contain $\mathrm{Sn} / \mathrm{SnO}_{\mathrm{X}}$ nanoparticles in the pores and its electrochemical performance as an anode material for lithium ion batteries. Carbon 2011, 49, 89-95.

131. Xuyen, N.T.; Ra, E.J.; Geng, H.-Z.; Kim, K.K.; An, K.H.; Lee, Y.H. Enhancement of conductivity by diameter control of polyimide-based electrospun carbon nanofibers. J. Phys. Chem. B 2007, 111, 11350-11353.

132. Merino, C.; Soto, P.; Vilaplana-Ortego, E.; Gomez de Salazar, J.M.; Pico, F.; Rojo, J.M. Carbon nanofibres and activated carbon nanofibres as electrodes in supercapacitors. Carbon 2005, 43, 551-557.

133. Kim, C.; Kim, J.-S.; Kim, S.-J.; Lee, W.-J.; Yang, K.-S. Supercapacitors prepared from carbon nanofibers electrospun from polybenzimidazol. J. Electrochem. Soc. 2004, 151, A769-A773.

134. Arshad, S.N.; Naraghi, M.; Chasiotis, I. Strong carbon nanofibers from electrospun polyacrylonitrile. Carbon 2011, 49, 1710-1719.

(C) 2014 by the authors; licensee MDPI, Basel, Switzerland. This article is an open access article distributed under the terms and conditions of the Creative Commons Attribution license (http://creativecommons.org/licenses/by/3.0/). 